\title{
Thermal Expansion of Platinum And Platinum-Rhodium Alloys
}

\section{Volume 91}

Number 6

November-December 1986

\author{
R. E. Edsinger, M. L. Reilly, \\ and J. F. Schooley \\ National Bureau of Standards \\ Gaithersburg, MD 20899
}

\begin{abstract}
This paper contains descriptions of the construction and use over the temperature range $-27^{\circ} \mathrm{C}$ to $570^{\circ} \mathrm{C}$ of a Merritt-Saunders (optical interferometric) linear thermal expansion apparatus. Measurements of thermal expansion are reported for platinum and for two platinum-rhodium alloys (nominally $12 \mathrm{wt} \% \mathrm{Rh}$ and $20 \mathrm{wt} \%$ $\mathrm{Rh}$ ). Detailed analyses are given of the measurement uncertainties involved in the experiment and of the representa-
\end{abstract}

tion of the data by polynomials in the sample temperatures. The data show precision at the 1-ppm level and good agreement with results already published.

Key words: coefficient of thermal expansion; optical interferometry; platinum; platinum-rhodium alloys; thermal expansion.

Accepted: July 23, 1986

\section{Introduction}

An accurate knowledge of thermal expansion is required for several different types of metrological experiments [1-3].' One exacting need is found in the study of thermodynamic temperature by the method of "constant-volume" gas thermometry; despite its name, this method involves a careful accounting for the unavoidable change of the volume of the gas bulb with temperature, leading to a correction of measured pressure ratios by as much as several percent.

Careful measurements have been made on the thermal expansion of many materials, including both metallic elements and certain alloys [4]. In addition, approximate values of the thermal expansion properties of some metallic elements can be obtained from theoretical considerations. For ex-

About the Authors: All are with the Center for Basic Standards in NBS' National Measurement Laboratory.

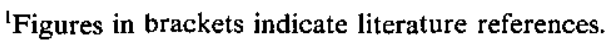

ample, using a monatomic model with centralforce interactions between nearest neighbors, MacDonald and MacDonald [5] have calculated values of the linear thermal expansion at temperature $T$ relative to that at reference temperature $T_{\text {ref }}$

$$
\epsilon\left(T, T_{\text {ref }}\right)=\left[L(\mathrm{~T})-\mathrm{L}\left(T_{\text {ref }}\right)\right] /\left[L\left(T_{\text {ref }}\right)\right]
$$

and of the coefficient of linear thermal expansion

$$
\begin{aligned}
\alpha\left(T, T_{\text {ref }}\right) & =\mathrm{d} / \mathrm{d} T \epsilon\left(T, T_{\text {ref }}\right) \\
& =[\mathrm{d} L(T) / \mathrm{d} T] /\left[L\left(T_{\text {ref }}\right)\right]
\end{aligned}
$$

for several metallic elements occurring in the facecentered cubic structure.

Despite the availability of either calculated or nominal measured values for the thermal expansion of the types of materials used in constructing a high-temperature gas thermometer, it is prudent for those who are interested in realizing the Kelvin Thermodynamic Temperature Scale by high-temperature gas thermometry to measure the thermal 
expansion on samples of the actual materials from which the gas bulb and capillary are to be fabricated, especially if these materials are alloys. The reason for this admonition is the great sensitivity, mentioned above, of the thermodynamic temperature determination to the thermal expansion of the gas-containing components.

There are several methods in use for the measurement of linear thermal expansion, ranging in sensitivity $\delta L / L$ from $10^{-5}$ to $10^{-11}$. Particular attention has been paid to the low-temperature region because of theoretical interest in deviations from the simple Grüneisen relation [6,7]. Existing methods include optical interferometry [8-10], $x$ rays [11], and the electrical measurement of capacitance of inductance [12,13].

This paper reviews the construction of a thermal expansion apparatus that permits measurement of length changes at the $1 \mathrm{ppm}$ level of accuracy and determination of sample temperatures that are accurate within $0.01{ }^{\circ} \mathrm{C}$. In addition, the results of thermal expansion measurements are reported for high-purity $\mathrm{Pt}$ and for two Pt-Rh alloys. The results of our measurements are analyzed in such a manner as to permit straightforward calculation of the quantities defined by eqs (1) and (2) and ready comparison with the results of other workers. The present experiments were performed in support of the National Bureau of Standards Gas Thermometry Program. Measurements were made over the range $-27^{\circ} \mathrm{C}$ to $570^{\circ} \mathrm{C}$. The method selected for the measurements was that of optical interferometry.

\section{Experimental}

\subsection{Thermal Expansion Furnace}

The thermal expansion furnace used in these experiments was designed in its original form by the late H. F. Stimson. Details of its present construction were provided by L. A. Guildner, former head of the NBS Gas Thermometry project, who also supervised its fabrication and the acquisition of the data discussed in this report. The thermal expansion apparatus was designed for use over the range $-30^{\circ} \mathrm{C}$ to $+700^{\circ} \mathrm{C}$. Of paramount importance was the attainment of temperature homogeneity within $0.01{ }^{\circ} \mathrm{C}$ over the volume occupied by the sample. It was necessary, of course, to provide a light path for the interferometric measurements and to allow the accurate measurement of the sample temperature. Accomplishment of these objectives required the multi-chambered, sealed furnace that is shown in cross section in figure 1.
The use of several radiation shields and structural shells to improve temperature homogeneity within a cryostat or furnace is a well-established technique; in this case, shell I1 carries the main heater assembly, a group of five independent resistive units. Shells 12 and 13 also are equipped with heaters, as noted in the caption of figure 1 .

Differential thermopiles allow direct comparison of the temperatures of the top plate of I1, the upper portion of its side wall, the middle portion of its side wall, and the lower portion of its side wall with that of its bottom plate. Similarly, the temperatures of the top plate and the side wall of 12 can be compared with that of its bottom plate. Finally, a thermopile also was installed on the surface of shell I3. Use of these thermopile circuits assists the operator in attempting to minimize internal temperature gradients.

Both the quartz window and the platinum resistance thermometer are sealed into the furnace by O-rings. As noted in figure 1, the furnace can be evacuated so that the operator can vary the pressure and type of gas in the furnace.

\subsection{Interferometer}

The linear thermal expansion of each sample was determimed by the Fizeau interferometer method described by Candler [15] and Merritt [16] and refined by Saunders [17]. In fact, the optical instrument used in this work was one formerly used by Saunders, but modified by the substitution of a ${ }^{198} \mathrm{Hg}$ light source in place of the original helium lamp. A schematic drawing of the optical arrangement is given in figure 2 .

The principle of the Merritt-Saunders thermal expansion determination is not complex, and it has the further advantage of usefully high precision. A lamp, in this case a low-pressure ${ }^{198} \mathrm{Hg}$, electrodeless, water-cooled tube excited by microwave energy, provides light that is collimated by a lens $L$, then dispersed by a prism DP in order to restrict its wavelength range to that of the ${ }^{198} \mathrm{Hg}$ line at 546.2 $\mathrm{nm}$. The light reflected by the two inner faces of the glass plates $\mathrm{A}$ and $\mathrm{B}$ forms an interference pattern when viewed through the eyepiece $\mathrm{E}$ or when imaged on the film $F$. The interference pattern follows the relation

$$
N \lambda_{0}=2 n L \cos \Theta
$$

where $N$ is the number of fringes, $\lambda_{0}$ is the vacuum wavelength in $\mu \mathrm{m}$ of the incident light, $n$ is the index of refraction of the medium between the plates, $L$ is the separation of the plates in $\mu \mathrm{m}$, and 


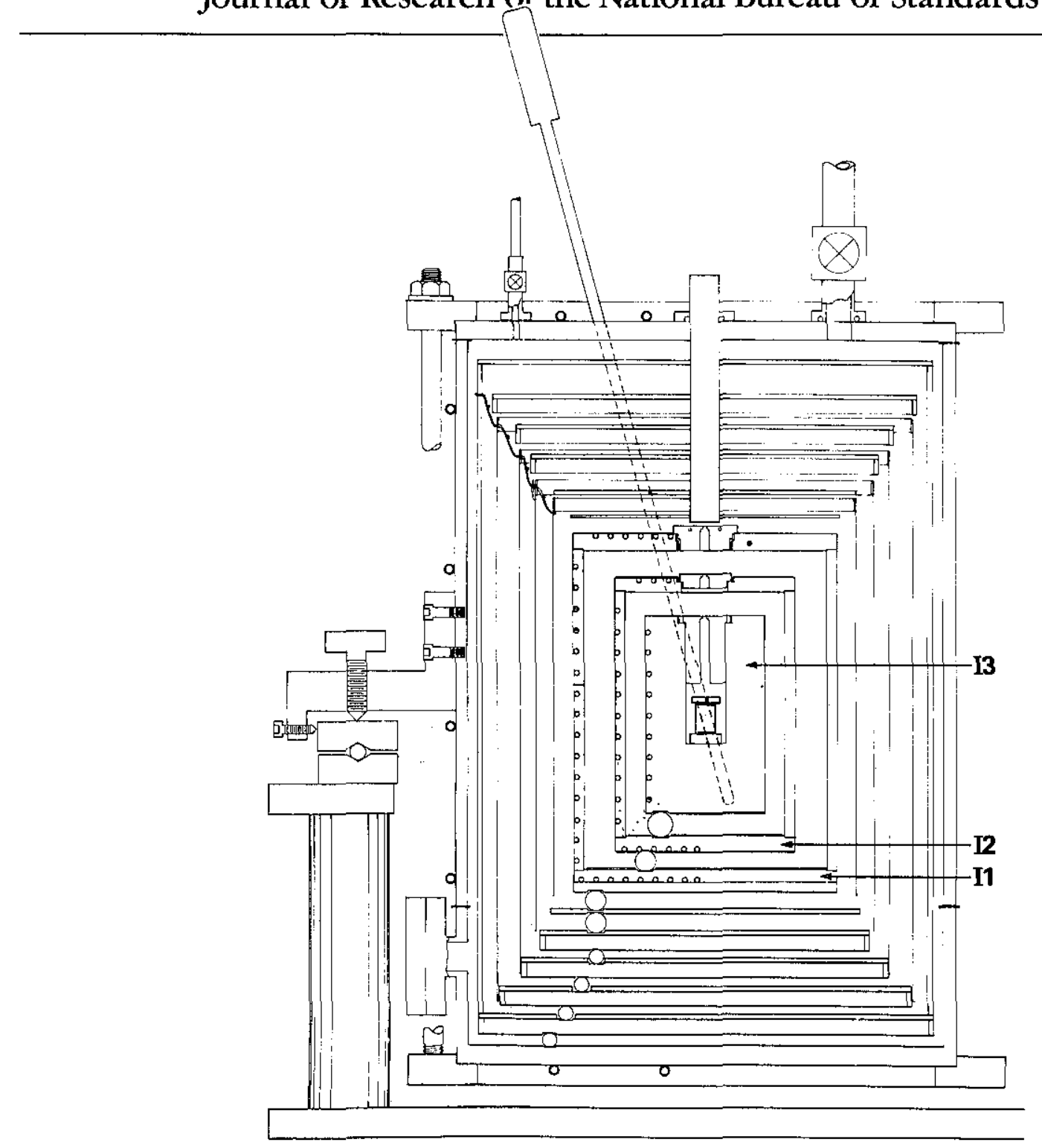

Figure 1-Schematic drawing of the thermal expansion furnace. The outermost shell, made of brass, is sufficiently strong so as to permit evacuation of the furnace. The brass shell also can be cooled to $-30^{\circ} \mathrm{C}$ by virtue of cooling coils on its exterior surface. Inside the brass shell is a radiation shield made of copper. The three shields immediately within the copper one are made of silver in order to provide surfaces of high radiant reflectivity. A highly reflective gold foil shield, supported at the top and bottom by "Inconel 600 " [14] plates, surrounds the largest of three Inconel shells. The silver and gold radiation shields are constructed with separate side walls which are suspended by hook-and-eye sets, beginning with hooks set into the copper shield, as shown in the figure. The Inconel shell, I1, is equipped with separate resistive heaters placed in grooves in its top, bottom, upper sidewall, mid- dle sidewall, and lower sidewall. The middle Inconel shell, 12, was prepared with three heater circuits located on its top plate, its sidewall, and its bottom plate. The innermost shell, I3, has a single heater on its sidewall. 13 was prepared from a solid, $7.5 \mathrm{~cm}$ diam by 13 $\mathrm{cm}$ long block of Inconel; a central hole was bored in it for enclosure of the sample assembly, and a diagonal hole was bored in its body as a socket for a platinum resistance thermometer. In the text, shell I3 is also identified as the sample tempering block. The bottom plates of the shields and Inconel shells rest upon sets of three steel ball bearings that are located in slots in the next lower plate; this technique provides a low-thermal-conductivity, yet a strong and flexible support for the furnace. The brass outer shell was assembled in three sections--a top plate, a cylindrical side wall, and a bottom plate. Polytetrafluorethylene gaskets, compressed by a set of screw clamps, provide the primary vacuum seal for the brass shell. The furnace is leveled and positioned by three sets of screws as shown. These screws make contact with a ball race that is rigidly fixed to the laboratory bench. Three-element "Platinel" [14] thermopiles are arrayed on the I1, I2, and I3 surfaces. These thermopiles are connected in differential circuits for use in temperature control. A quartz window, $1.9 \mathrm{~cm}$ diam and $16 \mathrm{~cm}$ long, is sealed in place above the sample and the interferometer plates. Insertion of a sample into the furnace is accomplished by removal of the top plate of the brass shell. The top plates of the radiation shields are interconnected by "Inconel X" [14] wires, so that all of these top plates are removed as a unit. Removal of the plugs in the Inconel shells I1, I2, and I3 then permits removal and replacement of the sample assembly. 


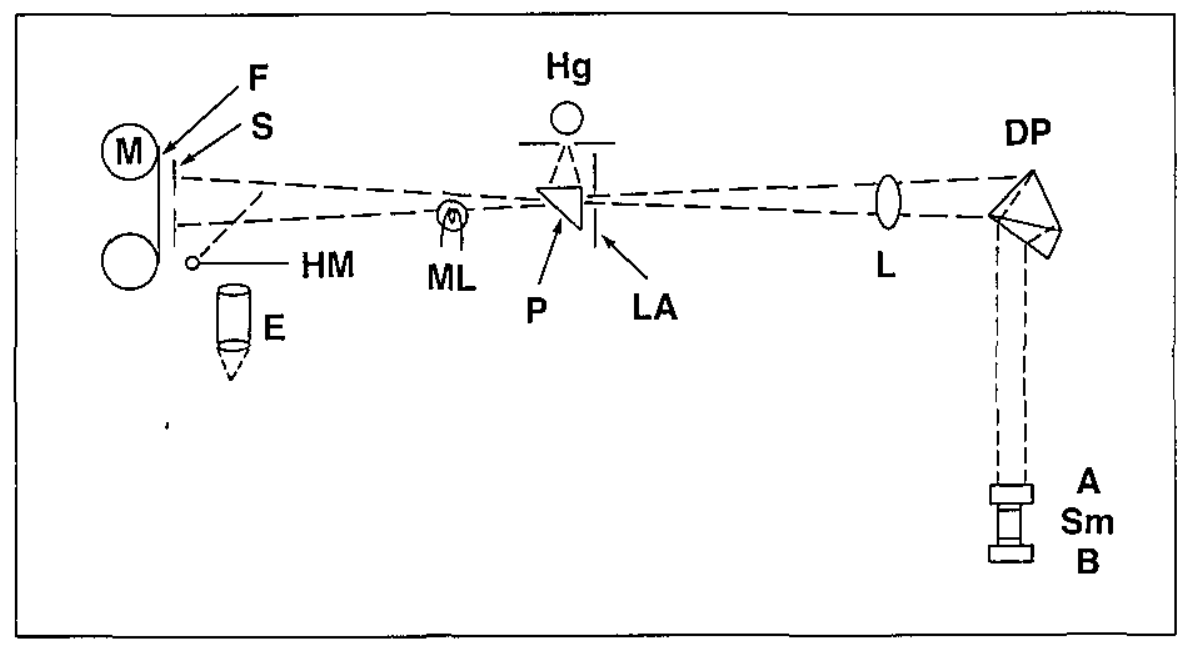

Figure 2-The recording interferometer schematically. M-Film drive motor. F-Film. S-Slit. HM-Hinged mirror. E-Eyepiece. $\mathbf{M L}-$ Marker lamp. $\mathbf{H g}-$ ${ }^{198} \mathrm{Hg}$ lamp. $\mathbf{P}-$ Simple prism. LA-Limiting aperture. $\mathbf{L}-$ Collimating lens. DP-Double dispersion prism. $\mathbf{A}, \mathbf{B}-$-Interferometer plates. $\mathbf{S m}-$ Sample. $\theta$ is the angle between the incident light rays and the normal to the lower reflecting surface atop the sample.

Furthermore, as the sample expands or contracts with changes in its temperature, the interference pattern undergoes a corresponding change because $L$ changes. By imaging the interference pattern on the film, the operator can obtain a permanent record for later evaluation. The eyepiece can be used in conjunction with the hinged mirror HM to observe the proper alinement of the optical system. In order to avoid the presence of unwanted interference effects, it is necessary that the upper surface of the top interferometer plate $A$ form an angle--in this case $20^{\prime}-$ with respect to the interfering surfaces. Similarly, it is necessary to tilt slightly the lens and the dispersing prism so as to eliminate any interference effects from them.

If the two interfering surfaces of the sample assembly plates A and B were to be made exactly parallel, then the interference pattern would consist of a single broad fringe. In that case, the viewer would see the entire assembly lighten and darken as the sample length expanded or contracted. In the Merritt-Saunders method, however, the upper interfering surface, shown in figure 3 as the underside of plate $\mathrm{A}$, is caused to tilt slightly in order to provide several parallel interference fringes. This tilting is arranged by making the sample length at the location of the pads a-a either longer or shorter than it is at the location of the pads $b-b$ and $c-c$. From eq (3), it can be deduced that the difference in the number of fringes at the two edges of the sample assembly, $\Delta N$, depends upon the difference in separation of the two interfering surfaces at their edges, $\Delta L$, according to the relation $\Delta N=2 n \Delta L$ $\cos \theta / \lambda_{0}$. In this manner, the changing position of the fringe pattern with respect to the fiducial mark can be determined with a resolution that is substantially better than \pm 1 fringe. The fiducial mark is provided by a fine $\mathrm{Pt}$ wire $\mathrm{W}$ that is fastened onto the sample between upper pads $b$ and $c$.

The fringe pattern that is obtained from a properly alined optical system is shown in figure 3 . The circular diagram on the lower left of figure 3 shows the pattern as seen by the operator while viewing through the eyepiece before assembly of the slotted plugs in I1, I2, and I3. We have found that the fringe pattern appears to change position slightly with respect to the fiducial mark as the optical aperture is decreased to sharpen the fringe image. It is necessary during this process also to adjust the position of the furnace so that the fringe image does not disappear entirely.

The lower middle diagram shows the fringe pattern as it appears at the film plane after partial masking by the slits in the plugs of shells I1-I3 and the slit $\mathrm{S}$. Note that the position of the fringe pattern can readily be measured with respect to the fiducial mark provided by the wire W. During measurements the operator correlates the position of the film with the measured furnace temperature, making use of the known rate of film advance and tagging the film record at known times by use of the marker lamp ML. The film drive motor $M$ is activated during any change in furnace temperature and for some time while a new temperature is being measured. The lower right diagram shows a typical filmed record of the fringe pattern. At the time $t_{1}$, a change in the furnace temperature is signaled by deviation of the fringe pattern from the direction parallel to the fiducial mark. By counting the fringes as they pass the fiducial mark, the operator can follow the progress of the sample thermal expansion. 
Figure 3-Relation of filmed fringe progression to the sample-plate assembly. A,BInterference plates. $\mathbf{a}-\mathbf{a}, \mathbf{b}-\mathbf{b}, \mathbf{c}-\mathbf{c}--$ Pads left on the sample edges to maintain the separation of the interfering surfaces of plates $A$ and $B$ and to provide a suitable interference fringe pattern. Sm--Sample. $\mathbf{S}$--Slit. F--Film. $\mathbf{t}_{1}$--time at which furnace temperature begins to change.
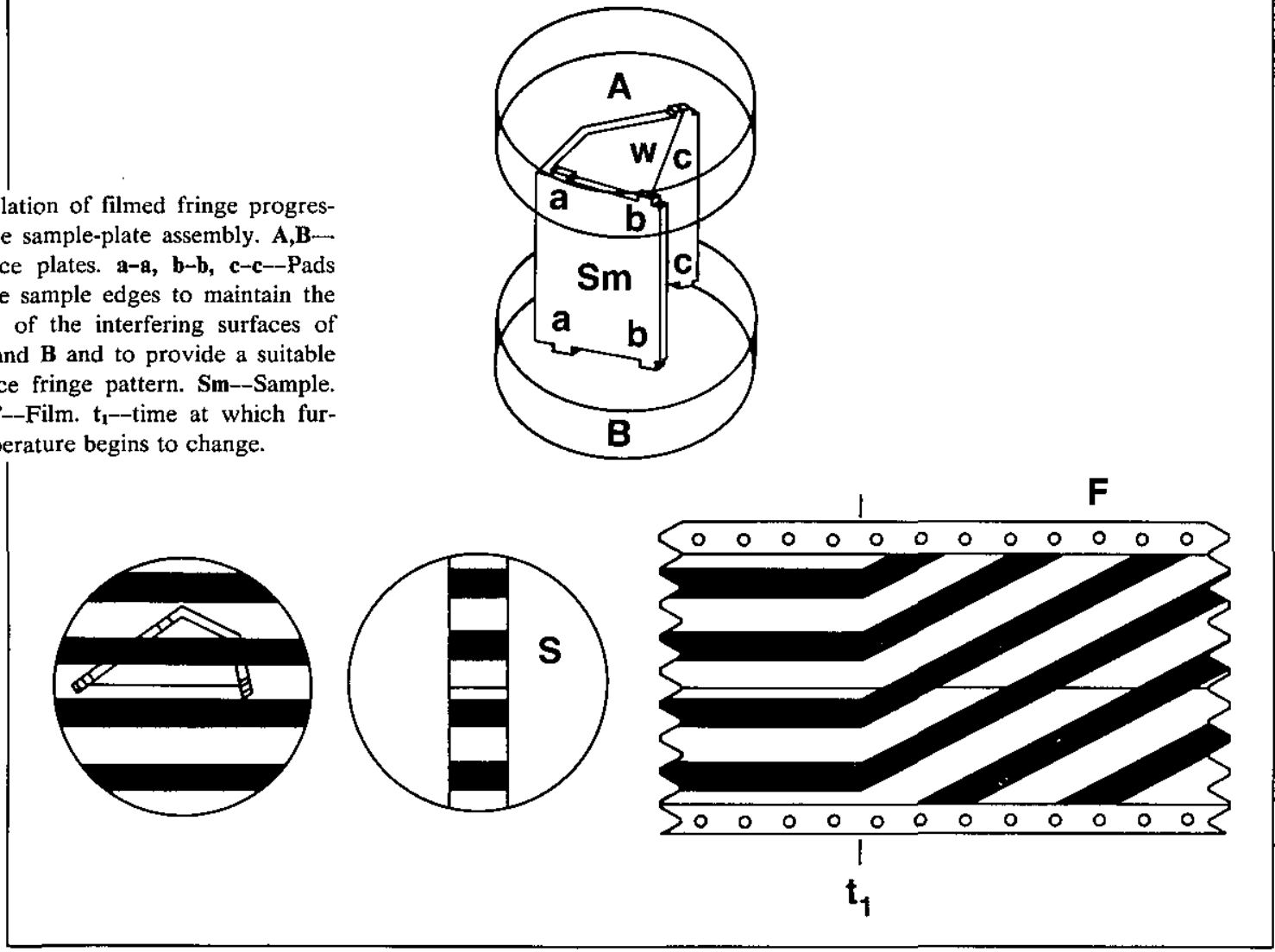

\subsection{Sample Assembly}

The thermal expansion measurements were performed on samples made either from surplus materials used in constructing gas bulbs for the NBS Gas Thermometer or from pieces cut from used gas bulbs. Most material was about $1 \mathrm{~mm}$ thick.

The general shape of the samples is shown in figure 3 . After cutting the material into a strip 22$25 \mathrm{~mm}$ by $\sim 50 \mathrm{~mm}$, re-cutting it so as to produce three sets of pads as shown in the figure, and bending it into the desired shape, a $0.08 \mathrm{~mm}$ platinum wire was wedged tightly in place into thin grooves in the sample pads $\mathrm{b}$ and $\mathrm{c}$ as a fiducial marker. The sample was annealed in $\mathrm{He}$ gas at $1100^{\circ} \mathrm{C}$ for $1 \mathrm{~h}$.

Circular optical flats of fused silica were used to generate the interference fringe pattern. The upper plate (A, figs. 2 and 3), was $2.2 \mathrm{~cm}$ in diam and 0.4 $\mathrm{cm}$ thick. As mentioned above, it was cut with an angle of approximately $20^{\prime}$ between its upper and lower surfaces so that no visible interference pattern would occur as a result of reflections from its upper surface. The lower plate (B, figs. 2 and 3 ), was $2.4 \mathrm{~cm}$ in diam and $0.7 \mathrm{~cm}$ thick. The lower surface of plate $A$ and the upper surface of $B$ were coated with $\mathrm{TiO}_{2}$ so as to optimize the performance of the optical system (i.e., total reflection by the upper surface of $B, \sim 30 \%$ reflectivity by the lower surface of A). The bottom surface of plate B was frosted so as to eliminate any interference therefrom.

The lengths between pairs of sample pads were measured using gage blocks and a precision micrometer of $2.6 \mathrm{~cm}$ capacity. By wringing together a suitable set of gage blocks, the operator could closely approximate the distance separating the surfaces of paired sample pads. Careful trimming and polishing of the pads, combined with micrometer measurement in a controlled temperature environment allowed the operator to measure and match the two sets of pads $b-b$ and $c-c$ within $0.25 \mu \mathrm{m}$. The separation between pads a-a was purposely made about $1 \mu \mathrm{m}$ longer than for the other two sets in order to provide the necessary angle between the reflecting surfaces of plates $\mathbf{A}$ and $\mathbf{B}$ to generate three or four fringes, as noted above.

\subsection{Thermometry}

The temperature of the sample chamber is determined through the use of a specially-made plat- 
inum resistance thermometer (PRT) of $R\left(0^{\circ} \mathrm{C}\right)$ about $2.5 \Omega$. The four-lead resistor element is made of high-purity platinum wire of $0.13 \mathrm{~mm}$ diam wound in the form of a bifilar, simple helix. The protective sheath is made of synthetic vitreous silica; it is $40 \mathrm{~cm}$ long, $7 \mathrm{~mm}$ diam. The thermometer is filled with a mixture of gases; $90 \% \mathrm{Ar}, 10 \% \mathrm{O}_{2}$. Thermometers made in this manner can be calibrated according to the procedures recommended in the text of the 1968 International Practical Temperature Scale [18] so as to provide IPTS-68 temperatures that are accurate within $\pm 0.002^{\circ} \mathrm{C}$ from $0{ }^{\circ} \mathrm{C}$ to $630^{\circ} \mathrm{C}$. Moreover, they can be used at temperatures as high as $1100^{\circ} \mathrm{C}$ with levels of imprecision as low as $\pm 0.02{ }^{\circ} \mathrm{C}$. The resistance values of the thermometer used in the thermal expansion apparatus were obtained by means of an ac resistance bridge designed by Cutkosky of the NBS [19].

In practice, the thermometer was calibrated in the NBS Platinum Resistance Thermometry Calibration Laboratory at the triple point of water, at the tin freezing point and at the zinc freezing point. The usual relations were then employed to obtain values of temperature on the IPTS-68 in the range $-27^{\circ} \mathrm{C}$ to $630^{\circ} \mathrm{C}$. This range was sufficient to satisfy the needs of this experiment. Possible drift in the thermometer calibration was monitored by periodic re-calibration at the water triple point in the Gas Thermometry Laboratory. We estimate the uncertainty in the thermometer calibration as no larger than $\pm 0.001^{\circ} \mathrm{C}$.

Uncertainty in the measured sample temperature also can arise from consideration of possible temperature gradients between the sample and its tempering block and between the block and the thermometer itself. We discuss these problems in some detail in section 4 .

\subsection{Temperature Control}

Control of the furnace temperature is achieved by use of differential thermocouples that are mentioned above, together with the platinum resistance thermometer. There are five independent heaters located on shell I1, three on shell I2, and one on shell I3 (this shell also is referred to as the sample tempering block); at any particular sample temperature, apportioning the required heat among these nine heaters is a complicated problem. Preparatory to making measurements at a particular temperature, the operator can adjust power to the heaters so as to minimize gradients within the shells $\mathrm{I} 1$ and I2. The temperatures of I1, I2, and I3 also can be adjusted to approximate equality. Finally, the operator can attempt to demonstrate temperature ho- mogeneity within the tempering block by changing the position of the platinum resistance thermometer. Any variation in its reading can arise from inadequate heater adjustment or from a more pernicious cause, inadequate thermal isolation from the room environment. Use of a special heater, not shown in figure 1 but located along the thermometer guide tube, allows the operator to evaluate the quality of the thermometer tempering.

In practice, the block I3 was supplied with a small extra amount of heat from its heater in order to maintain its temperature slightly above that of shell I2. In turn, shell I2 was maintained at a temperature slightly above that of shell I1. The overall objective was to apportion the power to the nine heaters so as to minimize the apparent gradient along block 13 .

All thermopile emf values were measured with a calibrated strip-chart recorder.

\subsection{Measurement Procedures}

In performing a determination of the thermal expansion of a particular sample, the first step consisted of preparing a sample assembly capable of providing reasonably straight interference fringes arrayed perpendicular to the slit in front of the camera, as noted above. The sample lengths at pads $\mathrm{a}-\mathrm{a}, \mathrm{b}-\mathrm{b}$, and $\mathrm{c}-\mathrm{c}$ were recorded, as was the temperature at which the measurement was performed.

Once the sample assembly was installed in the apparatus, the slotted plugs in shells I3, I2, and I1 and the shield covers were replaced and the furnace was evacuated prior to refilling with ${ }^{4} \mathrm{He}$ gas at a suitable pressure.

Sample temperatures were chosen with regard to the expected complexity of the curve of the thermal expansion coefficient vs temperature. Cooling below $0{ }^{\circ} \mathrm{C}$ was accomplished by Freon refrigerant flowing through the coils surrounding the outer brass shield. For temperatures above $0^{\circ} \mathrm{C}$, the voltages applied to the Inconel shell heaters were varied until the platinum resistance thermometer showed a resistance corresponding to the chosen temperature and until the temperature gradient within block I3 was minimized. Because of the long thermal response time of the apparatus, the time required to pass from one temperature to another one sometimes reached 24 hours.

The filmed fringe pattern that was obtained at each stable temperature was examined using a microdensitometer in order to determine the fractional fringe count at the fiducial mark to the nearest 0.001 fringe. Other experimental data recorded while the temperature was stable in- 
cluded the resistance of the sample PRT; the resistance of a temperature-controlled standard resistor (used in monitoring the stability of the resistance bridge); and the pressure of the ${ }^{4} \mathrm{He}$ gas in the apparatus.

During the time that the apparatus temperature was changing, the interferometer film system recorded the changing fringe pattern that resulted from the changing length of the sample. Evaluation of this film generally allowed a determination to be made of the whole number of fringes that passed the image of the fiducial mark during the corresponding temperature change. In certain cases, the recording system failed to operate; then the integral number of fringes involved in the measurement was estimated by means to be discussed in the next section.

\subsection{Analysis of Data}

In order to analyze our experimental data, we prepared tables that are keyed to the stable temperature values in chronological order. For each temperature, we listed the measured fractional fringe value associated with the position of the fiducial mark as well as the pressure of ${ }^{4} \mathrm{He}$ gas in the apparatus. We also listed the observed overall change in fringes, $\Delta N_{i}$, that accompanied each temperature change, $\Delta t_{i}$. These entries constitute the experimental data set for each sample.

In the relatively few cases in which the fringerecording system failed to operate during a change to a new temperature setting, we obtained an approximate value of the fringe change from a plot of $\Delta N_{i} / \Delta t_{i}$ vs the mean temperature of the interval. Such a plot was found to yield unambiguously the integral value of fringes passing the fiducial mark during a temperature change.

It is necessary to correct our fringe measurements for the effect of the index of refraction of the ${ }^{4} \mathrm{He}$ gas. This can be accomplished according to the relation

$$
\delta N\left(t_{i}\right)_{\text {vac-meas }}=2 L_{i} \cos \Theta\left(1-n_{i}\right) / \lambda_{0}
$$

where $\delta N\left(t_{i}\right)_{\text {vac-meas }}$ are the changes in the measured fringe counts at $t_{i}$ when corrected to vacuum conditions; the $L_{i}$ are the sample lengths at $t_{i}$ expressed in meters; $\cos \theta$ is essentially unity; $\lambda_{0}$, the vacuum wavelength of the ${ }^{198} \mathrm{Hg}$ line used in the experiment, is $546.2271 \times 10^{-9} \mathrm{~m} \mathrm{[20];} \mathrm{and} \mathrm{the} n_{i}$ are the indices of refraction of the ${ }^{4} \mathrm{He}$ gas contained in the apparatus at $t_{i}$. The $n_{i}$ can be calculated for each experimental temperature and pressure from the relation [21]

$$
n_{i}=1+(3.5 \pm 0.1) \times 10^{-5}\left[\frac{p_{i}}{101}\right]\left[\frac{293}{t_{i}+273}\right]
$$

where $p_{i}$ is expressed in $\mathrm{kPa}$ and $t_{\mathrm{i}}$ in degrees Celsius. It was sufficient to use $L_{\text {meas }}$ in place of $L_{i}$ since in no case was $\delta N\left(t_{i}\right)_{\text {vac-meas }}$ larger than 0.05 fringe.

Once we had corrected the observed fringe measurements for the presence of the ${ }^{4} \mathrm{He}$ gas, we could prepare a set of corrected values of $\Delta N\left(t_{i}, t_{i+1}\right)$ suitable for fitting.

We assumed that the linear thermal expansion of a particular sample, relative to $0{ }^{\circ} \mathrm{C}$ and expressed in experimental fringe units, could best be represented by a polynomial of the form

$$
N(t)=N\left(0^{\circ} \mathrm{C}\right)+\sum_{n=1}^{m} A_{n} t^{n}
$$

where $t$ is temperature in degrees Celsius.

The coefficients $A_{n}$ of eq (7) can be evaluated by fitting the function

$$
\Delta N\left(t_{i}, t_{i+1}\right)=\sum_{n=1}^{m} A_{n}\left(t^{n}{ }_{\mathrm{i}}-t^{n}{ }_{i+1}\right)
$$

to the experimental data. The coefficient $N\left(0^{\circ} \mathrm{C}\right)$ is subsequently obtained as

$$
N\left(0^{\circ} \mathrm{C}\right)=N\left(t_{\text {meas }}\right)-\sum_{n=1}^{m} A_{n} t_{\text {meas }}^{n}
$$

where $N\left(t_{\text {meas }}\right)$ is the length of the sample as measured at the known temperature $t_{\text {meas }}$ and expressed in experimental fringe units.

We fitted the corrected data for each sample, using eq (8) in a least-squares computational program with up to six coefficients. For each successive polynomial $(m=2,3, \ldots, 6)$ the program provided an estimated standard deviation of the fit and an analysis-of-variance test of the significance of the $m$ th coefficient [22]. This test provided us a useful criterion for selecting the degree of the polynomial that best fitted the data.

In fitting the data we gave zero weight to all points involving temperature changes less than $2{ }^{\circ} \mathrm{C}$. In every such case, however, these data points are included in the tables and plotted in the figures.

We arranged eq (7) to obtain the equation for the linear thermal expansion relative to $0{ }^{\circ} \mathrm{C}$ expressed in the form of eq (1).

$$
\epsilon\left(t, 0^{\circ} \mathrm{C}\right)=\left[L(t)-L\left(0^{\circ} \mathrm{C}\right)\right] / L\left(0^{\circ} \mathrm{C}\right)
$$




$$
\begin{aligned}
& =\left[N(t)-N\left(0^{\circ} \mathrm{C}\right)\right] / N\left(0^{\circ} \mathrm{C}\right) \\
& =\sum_{n=1}^{m}\left[A_{n} / N\left(0^{\circ} \mathrm{C}\right)\right] t^{n}
\end{aligned}
$$

For any other reference temperature, $\epsilon\left(t, t_{\text {ref }}\right)$ can be obtained as

$$
\epsilon\left(t, t_{\mathrm{ref}}\right)=\frac{\epsilon\left(t, 0^{\circ} \mathrm{C}\right)-\epsilon\left(t_{\mathrm{ref}}, 0^{\circ} \mathrm{C}\right)}{1+\epsilon\left(t_{\mathrm{ref}}, 0^{\circ} \mathrm{C}\right)} .
$$

Frequently, the experimental results are presented in the literature using a reference temperature of $293 \mathrm{~K}$ (i.e., $19.85^{\circ} \mathrm{C}$ ) and using temperatures expressed in kelvins [4]. For each sample, we present equations in this format using eq (11) to derive the appropriate coefficients.

\section{Results}

Thermal expansion data have been determined for three samples of $1 \mathrm{~mm}$ thickness; platinum sheet (Englehard Industries 99.95\%) [14], an alloy of nominal composition ( $88 \mathrm{wt} \% \mathrm{Pt}+12 \mathrm{wt} \% \mathrm{Rh}$ ), and an alloy of nominal composition ( $80 \mathrm{wt} \%$ $\mathrm{Pt}+20 \mathrm{wt} \% \mathrm{Rh})$.

\section{1 $100 \%$ Pt Sample}

As described above, the sample length at each set of pads (a-a, b-b, and c-c, fig. 3) was determined by the use of a calibrated gage block and a precision dial micrometer. The sample lengths were measured relative to the gage block at $22^{\circ} \mathrm{C}$. Since the gage block had been calibrated at $20^{\circ} \mathrm{C}$, to obtain the true lengths of the sample at $22^{\circ} \mathrm{C}$, it was necessary to adjust the gage block length for the actual temperature difference. The sample lengths at pads b-b and c-c agreed within $130 \mathrm{~nm}$. At pads a-a, the sample length was some $826 \mathrm{~nm}$ longer than the average length at the fiducial mark. The $22^{\circ} \mathrm{C}$ average length at the fiducial mark as $25.277090 \mathrm{~mm} \pm 130 \mathrm{~nm}$. This corresponds to $92,551.58 \pm 0.5$ fringes in vacuum.

Data at 26 stable temperatures were recorded on the above sample using the Merritt-Saunders interferograph over the range $-27.6^{\circ} \mathrm{C}$ to $567.7^{\circ} \mathrm{C}$. The data were recorded as two runs (Nos. 205 and 206) because a lapse of nearly one month separated observations No. 17 and No. 18. However, the apparatus was not disturbed during that time and, herein, we treat the data as one set. Column 2 of table 1 lists the stabilized temperature points in chronological order. Note that the data were not obtained in a single sweep through the temperature range of interest.
As noted earlier, the filmed fringe pattern that was obtained at each stable temperature was examined using a microdensitometer in order to determine the fractional fringe count at the fiducial mark to the nearest 0.001 fringe. This fractional fringe count is noted in column 3 of the table for each point.

In column 4 of table 1, we have reported the pressure in $\mathrm{kPa}$ of the ${ }^{4} \mathrm{He}$ gas that filled the thermal expansion apparatus during each stable temperature measurement. Using the refractive index for ${ }^{4} \mathrm{He}$, adjusted for the actual furnace temperature and pressure by means of eq (6), we corrected the fractional fringe count in column 3 of table 1 to vacuum conditions by use of eq (5). These corrected values are given in column 5 .

The corrected differences in total fringe count between successive stabilized temperatures, are given in column 6 of table 1 . Note that each entry in column 6 is placed between the two relevant entries for the stable-temperature points in columns $1-5$.

As noted in section 2.7, we used a polynomial of the form of eq (8) to fit the values of $\Delta N\left(t_{i}, t_{i+1}\right)$ by the method of least squares. A summary of the fitting parameters in given in table 2. As indicated in table 2 , the analysis-of-variance test for significance of the last coefficient showed the coefficient of the 4th degree term of the polynomial to be significant at the $95 \%$ level of confidence.

Using the 4th-degree coefficients given in table 2 , we calculated values of $\Delta N$ for successive experimental end-point temperatures; these are given in column 7 of table 1 .

In column 8 of table 1 are listed the differences $\left(\Delta N_{\text {expt }}-\Delta N_{\text {calc }}\right)$. These differences are plotted against the average sample temperature $\left(t_{i}+t_{i+1}\right) / 2$ in figure 4.

Using the relationship expressed by eq (10), the percent linear thermal expansion for $100 \% \mathrm{Pt}$ with $0{ }^{\circ} \mathrm{C}$ as the reference temperature is given by eq (12) where $N\left(0^{\circ} \mathrm{C}\right)=92,533.46$ fringes.

$$
\begin{aligned}
100 \epsilon\left(t, 0^{\circ} \mathrm{C}\right)= & 100 \sum_{n=1}^{4}\left[A_{n} / N\left(0^{\circ} \mathrm{C}\right)\right] t_{n} \\
= & 8.862 \times 10^{-4} t+1.760 \times 10^{-7} t^{2} \\
& \quad-1.144 \times 10^{-10} t^{3} \\
& +8.93 \times 10^{-14} t^{4}
\end{aligned}
$$


Table 1. Experimental Data for $100 \mathrm{Wt} \%$ Pt.

$N\left(22^{\circ} \mathrm{C}\right)=92,551.58 \pm 0.5$ fringes

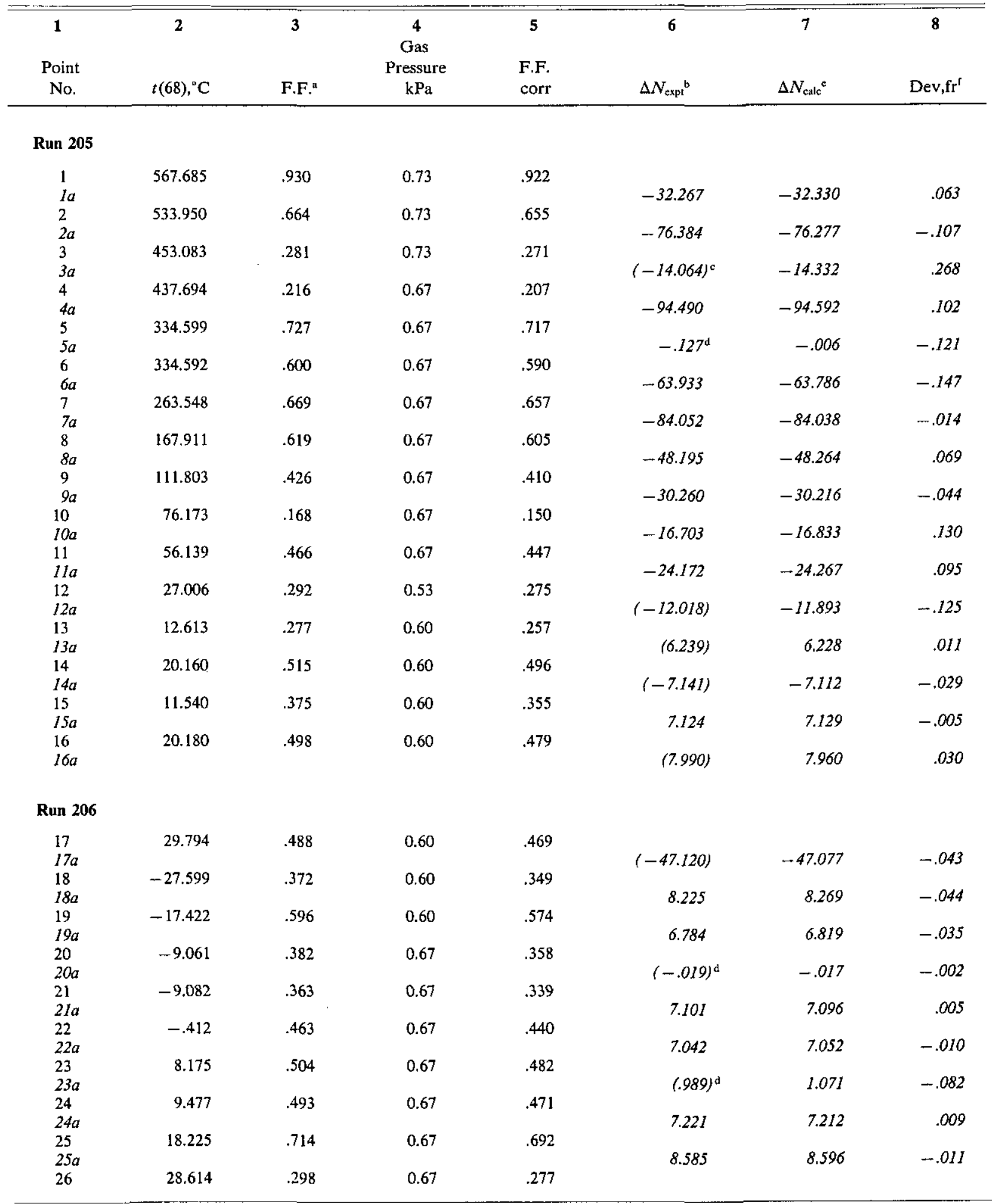

a F.F.; fractional fringe count at the fiducial mark.

b $\Delta N_{\text {expt }}$; corrected differences in sample length, expressed in fringes.

c Use of parentheses indicates that the integral number of fringes passing the fiducial mark during a particular temperature change was obtained from a trial plot of $\Delta N / \Delta t$ vs the mean temperature of the interval (see section 2.7 ).

d Data points $5 \mathrm{a}, 20 \mathrm{a}$, and $23 \mathrm{a}$ were given zero weight in the fitting procedure.

- $\Delta N_{\text {cale: }}$ fringe differences calculated for the end-point temperatures given in column 2, using eq (8) with the coefficients given in table 2.

' $\mathrm{Dev} ; \Delta N_{\text {expt }}-\Delta N_{\text {calc. }}$. These differences are plotted against the average experimental end point temperatures in figure 4. 
Table 2. Fitting parameters for the thermal expansion of $100 \%$ Pt.

Equation used in least-squares fitting procedure:

$$
\Delta N\left(t_{i}, t_{i+1}\right)=\sum_{n=1}^{m} A_{n}\left(t^{n}{ }_{i}-t^{n}{ }_{i+1}\right)
$$

Determination of number of polynomial terms $m$ for "best fit": $\mathrm{p}=22$ data points

\begin{tabular}{|c|c|c|c|}
\hline$m$ & $\sigma^{\mathrm{a}}$ & $F_{n t}^{\mathrm{b}}$ & $F_{0,95}(1, p-m)$ \\
\hline 1 & 1.7290 & & \\
\hline 2 & 0.1254 & $4 \overline{4537.7}$ & 4.35 \\
\hline 3 & 0.1101 & 7.7 & 4.38 \\
\hline 4 & 0.0985 & 6.5 & 4.41 \\
\hline 5 & 0.0987 & 0.9 & 4.45 \\
\hline 6 & 0.0990 & 0.9 & 4.49 \\
\hline
\end{tabular}

Coefficients of 4 th degree polynomial:

\begin{tabular}{ccl}
$n$ & \multicolumn{1}{c}{$A_{n}$} & \multicolumn{1}{c}{$\sigma$ of $A_{n}$} \\
$\frac{n}{1}$ & 0.8199876 & 0.0014412 \\
2 & 0.000162877 & 0.000012011 \\
3 & -0.000000105857 & 0.000000036848 \\
4 & 0.000000000082658 & 0.000000000034522 \\
$N\left(0^{\circ} \mathrm{C}\right)=92,533.46$ fringes [from eq $(9)$ ]
\end{tabular}

${ }^{a} \sigma ;$ the estimated standard deviation of the fit.

${ }^{b} F_{m}$; an index used to estimate the level of significance of the $m$ th coefficient in the equation fitted to the data.

$$
F_{m}=1+(p-m+1)\left[\left(\frac{\sigma_{m-1}}{\sigma^{m}}\right)^{2}-1\right]
$$

where $p$ is the number of data points and $m$ is the number of coefficients in the polynomial. The coefficient $A_{m}$ is considered significant at the desired level of confidence if $F_{m}$ is greater than the corresponding value given in the fourth column. (Entries in column 4 were taken from a standard table for the $F$-distribution, e.g., table III of [22].)

For a reference temperature of $293 \mathrm{~K}$ the corresponding equation is

$$
\begin{aligned}
100 \epsilon(T, 293 \mathrm{~K})= & -1.766 \times 10^{-2} \\
& +8.860 \times 10^{-4}(T-273.15) \\
& +1.760 \times 10^{-7}(T-273.15)^{2} \\
& -1.144 \times 10^{-10}(T-273.15)^{3} \\
& +8.93 \times 10^{-14}(T-273.15)^{4}
\end{aligned}
$$

\section{$3.2(88 w t \% \mathrm{Pt}+12$ wt\% Rh) Sample}

The (88 wt \% Pt+12 wt $\% \mathrm{Rh}$ ) sample was made with a geometric shape similar to that of the $100 \%$
Pt sample. The sample length at the position of the fiducial wire was measured against a gage block, again using a precision dial micrometer; the sample length was determined to be $21.039689 \mathrm{~mm} \pm 105$ $\mathrm{nm}$ at $26.7^{\circ} \mathrm{C}$, which corresponds to $77,036.42$ \pm 0.4 fringes in vacuum.

Thirty-seven stable temperature points were obtained on the $(\mathrm{Pt}+12 \% \mathrm{Rh})$ sample in two sets of measurements that were separated in time by four months. Table 3 shows the data in the same format as that presented in table 1 for $100 \% \mathrm{Pt}$, with the two sets of measurements separated for analytical purposes. Again it was necessary to deduce the integral number of fringes that crossed the fiducial mark in a few cases; these estimated values are enclosed in parentheses in column 6 .

We note that the analysis of two independent sets of thermal expansion data can help considerably to illuminate the overall level of reproducibility of our measurements. In principle, the thermal expansion data in the second set of measurements should duplicate the data in the first set; the sample, though removed from the apparatus, was not modified between measurements. Only an accidental sample length change owing to rough handling, a modification of the sample properties owing to the heating that occurred during the first measurement, or a mis-alinement of the optical system during re-assembly of the apparatus should cause any discrepancy between the two sets of data. Realizing these possibilities, we fitted the thermal expansion data for each data set separately as well as grouped into one large data set.

The values $\Delta N_{\text {calc }}$ listed in column 7 of table 3 were obtained by the use of the fitting coefficients given in table 4, along with the experimental endpoint temperatures. The differences $\left(\Delta N_{\text {expt }}-\Delta N_{\text {calc }}\right)$ are listed in column 8 of table 3 and they are plotted in figure 5 .

Although the analysis-of-variance test indicates that a fifth term is statistically significant even at the $99 \%$ confidence level, we choose to represent our data with a four-term equation. There are two reasons for making this choice. The first is that the observed data of Run 204 (15 of the 34 points which cover over $90 \%$ of the temperature range) can be unambiguously "best fitted" by a four-term equation from which the estimated standard deviation of the data is 0.018 fringe. The two data points from Run 207 which overlap the temperature range of Run 204 deviate by less than 0.005 fringe from the four-term equation fitted to Run 204. The 19 data points of Run 207 can be "best fitted" by a three-term equation from which the estimated standard deviation of the data is 0.020 fringe, a value 


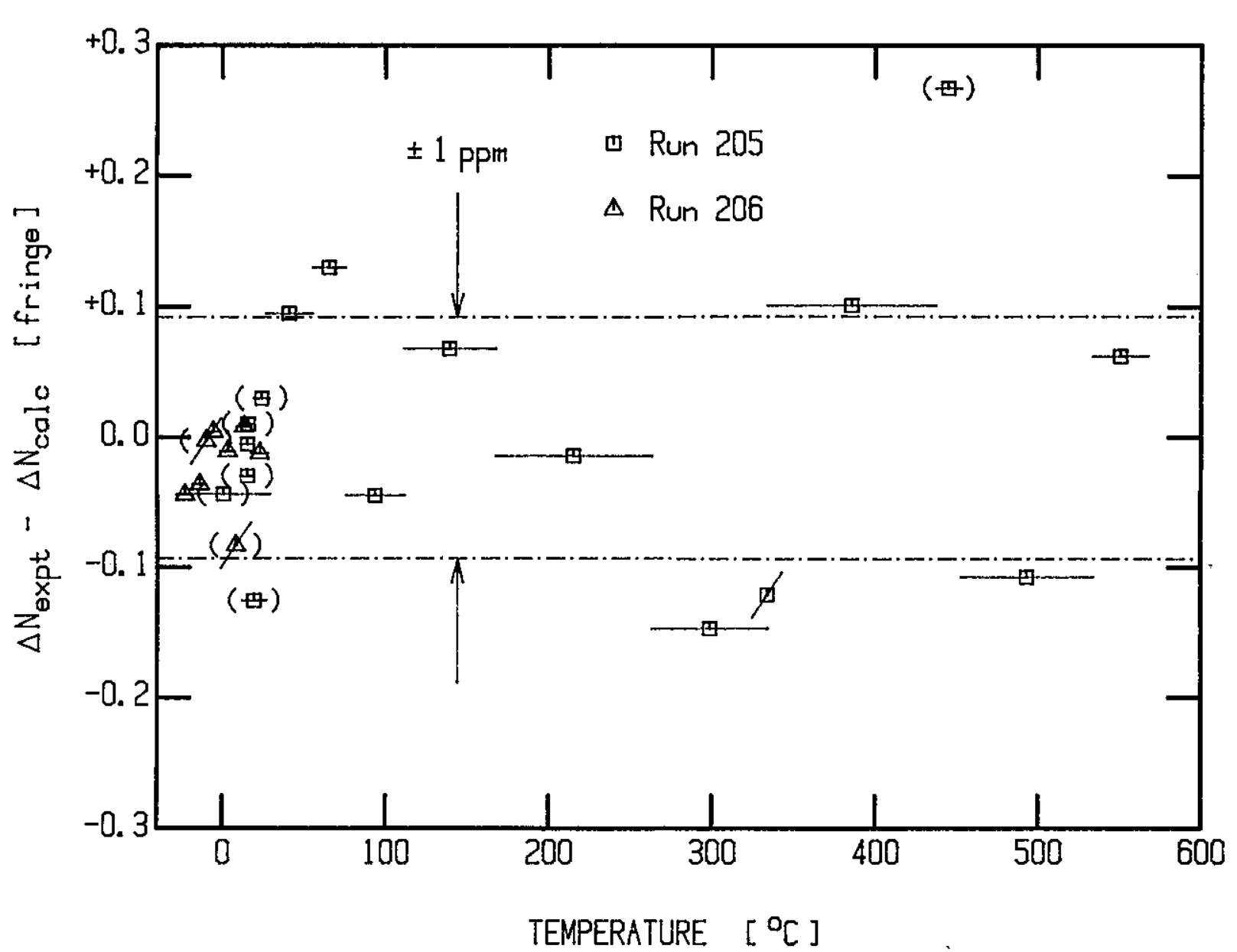

Figure 4-Differences in fringes of light at $546 \mathrm{~nm}$ between the length changes that were observed experimentally for $100 \%$ Pt and those that were calculated from the 4th degree fitting equation (see table 2). The squares indicate data of Run No. 205; the triangles, Run No. 206. The horizontal bar centered on each point denotes the temperature interval over which the length change was measured. () encloses a data point for which the whole number of fringes was estimated. / marks a data point that was given zero weight in the fitting process. $\ldots \cdot-\ldots$ indicates the bounds of one part per million in sample length.

comparable to that obtained when a five-term equation is fitted to all of the data. It appears that the imprecision of the data below $25^{\circ} \mathrm{C}$ allows an additional flexibility in the fitting process. This additional flexibility was also observed when the data for each of the three samples were fitted by two other model equations, indicating that there may be an unusual distribution of these data-though at a low level of imprecision.

The second reason for our choice of the fourterm equation is to maintain a consistent treatment of the data for each of the three samples. By so doing, we believe that the comparison of the differences between the calculated values for the thermal expansion of pure platinum and the two rhodium-platinum alloys will be least influenced by the analytical treatment of the experimental data. The consequences of choosing the four- rather than the five-term equation are very slight. In the range -20 to $550^{\circ} \mathrm{C}$, no value of linear expansion relative to $0^{\circ} \mathrm{C}$ calculated with the four-term equation differs by as much as $1 \mathrm{ppm}$ from that calculated with the five-term equation. This difference is less than the estimated uncertainty in the calculated value. The difference between the five- and four-term equation is indicated by the dotted line in figure 5 .

We suggest that the percent linear thermal expansion relative to $0{ }^{\circ} \mathrm{C}$, for $(88 \mathrm{wt} \% \mathrm{Pt}+12 \mathrm{wt} \%$ $\mathrm{Rh}$ ) be calculated using the relation

$$
\begin{aligned}
100 \epsilon\left(t, 0^{\circ} \mathrm{C}\right)= & 100 \sum_{n=1}^{4}\left[A_{n} / N\left(0^{\circ} \mathrm{C}\right)\right] t^{n} \\
= & 8.763 \times 10^{-4} t+2.116 \times 10^{-7} t^{2} \\
& \quad-1.455 \times 10^{-10} t^{3} \\
& +1.036 \times 10^{-13} t^{4}
\end{aligned}
$$

where $N\left(0^{\circ} \mathrm{C}\right)=77,018.29$ fringes. 
Journal of Research of the National Bureau of Standards

Table 3. Experimental data for ( $88 w t \% \mathrm{Pt}+12 w t \% \mathrm{Rh})$.

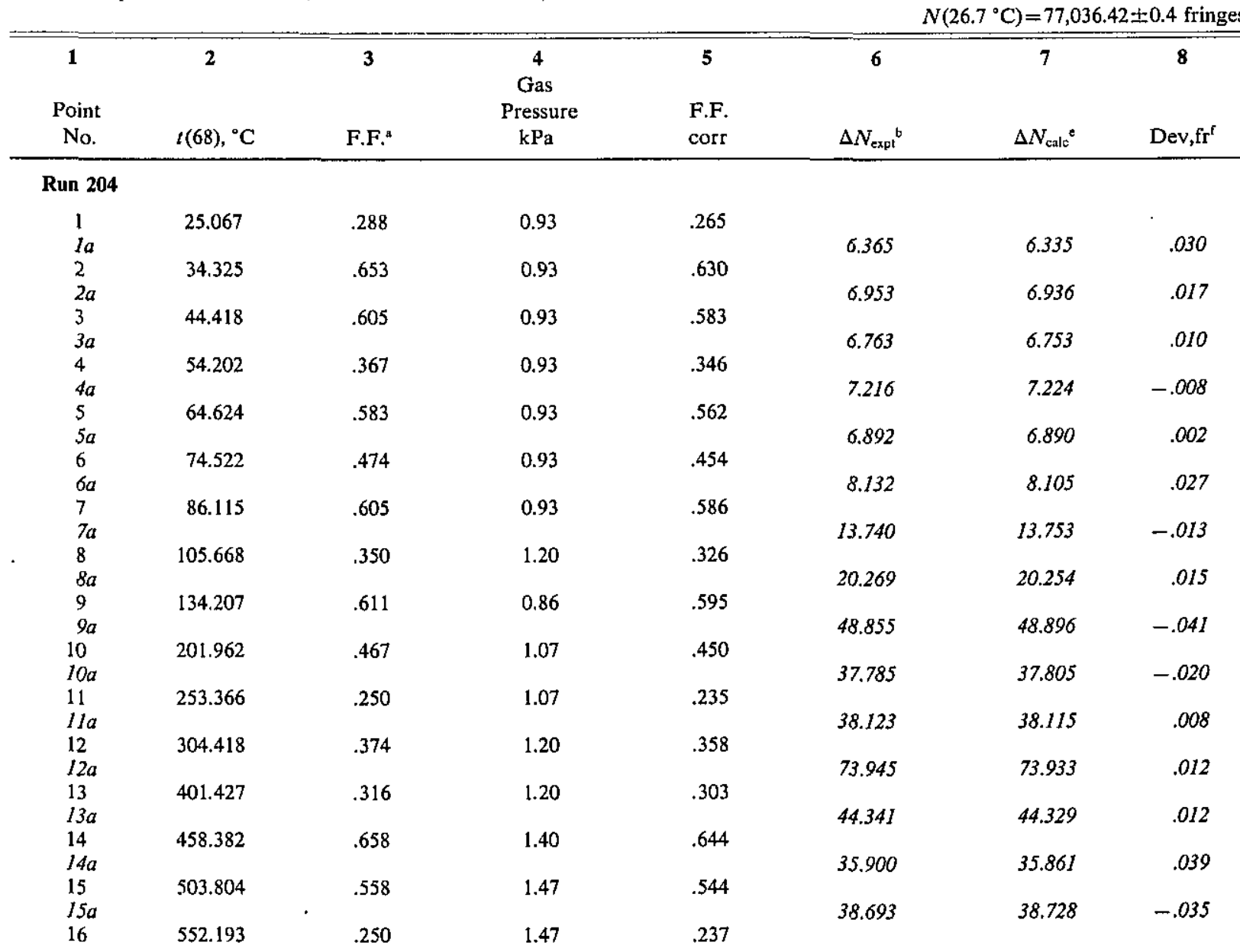

Run 207

\begin{tabular}{|c|c|}
\hline $\begin{array}{l}17 \\
17 a\end{array}$ & 272.145 \\
\hline $\begin{array}{l}18 \\
18 a\end{array}$ & 175.678 \\
\hline $\begin{array}{l}19 \\
19 a\end{array}$ & 28.981 \\
\hline $\begin{array}{l}20 \\
20 a\end{array}$ & -17.700 \\
\hline 21 & -12.361 \\
\hline $\begin{array}{l}22 \\
22 a\end{array}$ & -7.974 \\
\hline $\begin{array}{l}23 \\
23 a\end{array}$ & -3.001 \\
\hline $\begin{array}{l}24 \\
24 a\end{array}$ & 2.807 \\
\hline $\begin{array}{l}25 \\
25 a\end{array}$ & 13.010 \\
\hline $\begin{array}{l}26 \\
26 a\end{array}$ & 23.443 \\
\hline $\begin{array}{l}27 \\
27 a\end{array}$ & 24.983 \\
\hline $\begin{array}{l}28 \\
28 a\end{array}$ & -13.120 \\
\hline $\begin{array}{l}29 \\
29 a\end{array}$ & -22.757 \\
\hline $\begin{array}{l}30 \\
30 a\end{array}$ & -18.147 \\
\hline $\begin{array}{l}31 \\
31 a\end{array}$ & -13.292 \\
\hline
\end{tabular}

$\begin{array}{ll}0.53 & .367 \\ 0.53 & .548 \\ 0.53 & .127 \\ 0.40 & .576 \\ 0.40 & .121 \\ 0.40 & .062 \\ 0.40 & .430 \\ 0.67 & .319 \\ 0.67 & .245 \\ 0.53 & .321 \\ 0.53 & .406 \\ 0.33 & .625 \\ 0.13 & .188 \\ 0.40 & .242 \\ 0.27 & .504\end{array}$

$\begin{array}{rrr}-70.819 & -70.859 & .040 \\ (-103.421)^{\mathrm{c}} & 103.372 & -.049 \\ (-31.551) & -31.588 & .037 \\ 3.545 & 3.577 & -.032 \\ 2.941 & 2.946 & -.005 \\ 3.368 & 3.347 & .021 \\ 3.889 & 3.920 & -.031 \\ 6.926 & 6.912 & .014 \\ (7.076) & 7.102 & -.026 \\ (1.085)^{\mathrm{d}} & 1.051 & .034 \\ (-25.781) & -25.788 & .007 \\ -6.437 & -6.447 & .010 \\ 3.054 & 3.080 & -.026 \\ 3.262 & 3.251 & .011 \\ 2.806 & 2.845 & -.039 \\ & & \text { (Continued) }\end{array}$


Table 3 Continued. Experimental data for ( $88 \mathrm{wt} \% \mathrm{Pt}+12 \mathrm{wt} \% \mathrm{Rh})$.

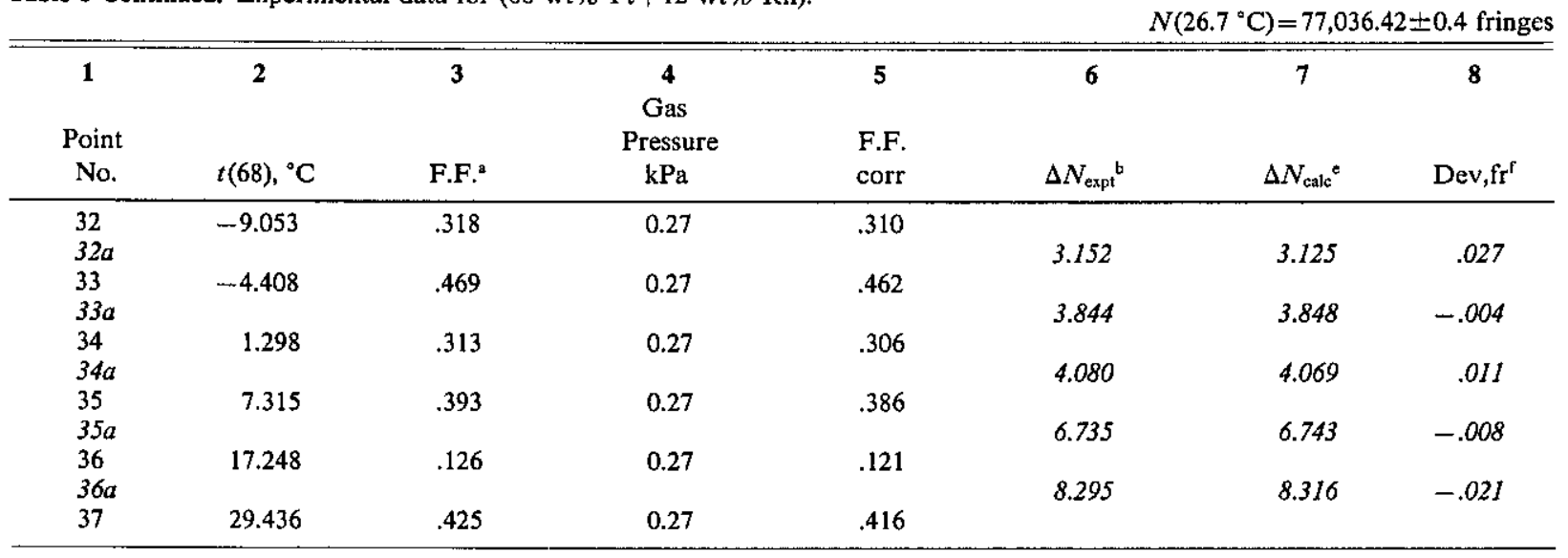

F.F.; fractional fringe count at the fiducial mark.

b $\Delta N_{\text {expt; }}$ corrected differences in sample length, expressed in fringes.

- Use of parentheses indicates that the integral number of fringes passing the fiducial mark during a particular temperature change was obtained from a trial plot of $\Delta N / \Delta t$ vs the mean temperature of the interval (see section 2.7 ).

d Data point 26 a was given zero weight in the fitting procedure.

e $\Delta N_{\text {calc }}$; fringe differences calculated for the end-point temperatures given in column 2, using eq (8) with the coefficients given in table 4 .

' Dev; $\Delta N_{\text {expt }}-\Delta N_{\text {cale. }}$ These differences are plotted against the average experimental end-point temperatures in figure 5 .

Table 4. Fitting parameters for the thermal expansion of (88 wt\% Pt $+12 \mathrm{Rh}$ ).

Equation used in least-squares fitting procedure:

$$
\Delta N\left(t_{i}, t_{i+1}\right)=\sum_{n=1}^{m} A_{n}\left(t^{n},-t^{n}{ }_{i+1}\right)
$$

Determination of number of polynomial terms $m$ for "best fit": $\mathbf{p}=34$ data points

\begin{tabular}{|c|c|c|c|}
\hline$m$ & $\sigma^{a}$ & $F_{m}{ }^{\mathrm{b}}$ & $F_{0.95}(1, p-m)$ \\
\hline 1 & 1.4087 & 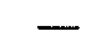 & $\longrightarrow$ \\
\hline 2 & 0.0912 & 8086.2 & 4.15 \\
\hline 3 & 0.0493 & 80.8 & 4.16 \\
\hline 4 & 0.0259 & 85.1 & 4.17 \\
\hline 5 & 0.0205 & 19.4 & 4.18 \\
\hline 6 & 0.0204 & 1.2 & 4.20 \\
\hline
\end{tabular}

Coefficients of 4 th degree polynomial:

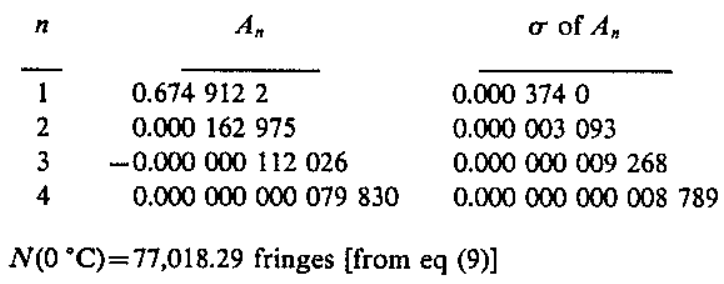

\footnotetext{
a $\sigma$; the estimated standard deviation of the fit.

${ }^{b} F_{m}$; an index used to estimate the level of significance of the $m$ th coefficient in the equation fitted to the data.
}

$$
F_{m}=1+(p-m+1)\left[\left(\frac{\sigma_{m-1}}{\sigma^{m}}\right)^{2}-1\right]
$$

where $p$ is the number of data points and $m$ is the number of coefficients in the polynomial. The coefficient $A_{m}$ is considered significant at the desired level of confidence if $F_{m}$ is greater than the corresponding value given in the fourth column. (Entries in column 4 were taken from a standard table for the $F$-distribution, e.g., table III of [22].)
For a reference temperature of $293 \mathrm{~K}$ the corresponding equation is

$$
\begin{aligned}
100 \epsilon(\mathrm{T}, 293 \mathrm{~K})= & -1.747 \times 10^{-2} \\
& +8.761 \times 10^{-4}(T-273.15) \\
& +2.116 \times 10^{-7}(T-273.15)^{2} \\
& -1.454 \times 10^{-10}(T-273.15)^{3} \\
& +1.036 \times 10^{-13}(T-273.15)^{4}
\end{aligned}
$$

\section{$3.3(80 w t \% P t+20 w t \%$ Rh) Sample}

The ( $80 \mathrm{wt} \% \mathrm{Pt}+20 \mathrm{wt} \% \mathrm{Rh})$ sample was prepared in a manner similar to those used with the other two samples. Its length at $21^{\circ} \mathrm{C}$ was determined as $21.380463 \mathrm{~mm} \pm 107 \mathrm{~nm}$, corresponding to $78,284.15 \pm 0.4$ fringes in vacuum.

The $25 \Delta N\left(t_{i}, t_{i+1}\right)$ data points measured with this sample are displayed in table 5 , using the same format that was employed for tables 1 and 3 .

Again we used the method of least squares with a polynomial in $t$ to fit the data in the form $\Delta N\left(t_{i}, t_{i+1}\right)$. A summary of the fitting parameters is given in table 6 . Note that the $F$ test indicates significance of the $t^{4}$ term at the $95 \%$ level of confidence.

Using the fourth-degree coefficients given in table 6, we calculated values of $\Delta N$ for the experimental end-point temperatures, as we did with the other two samples, as well as the differences $\left(\Delta N_{\text {expt }}-\Delta N_{\text {calc }}\right)$. These sets of values are given in 


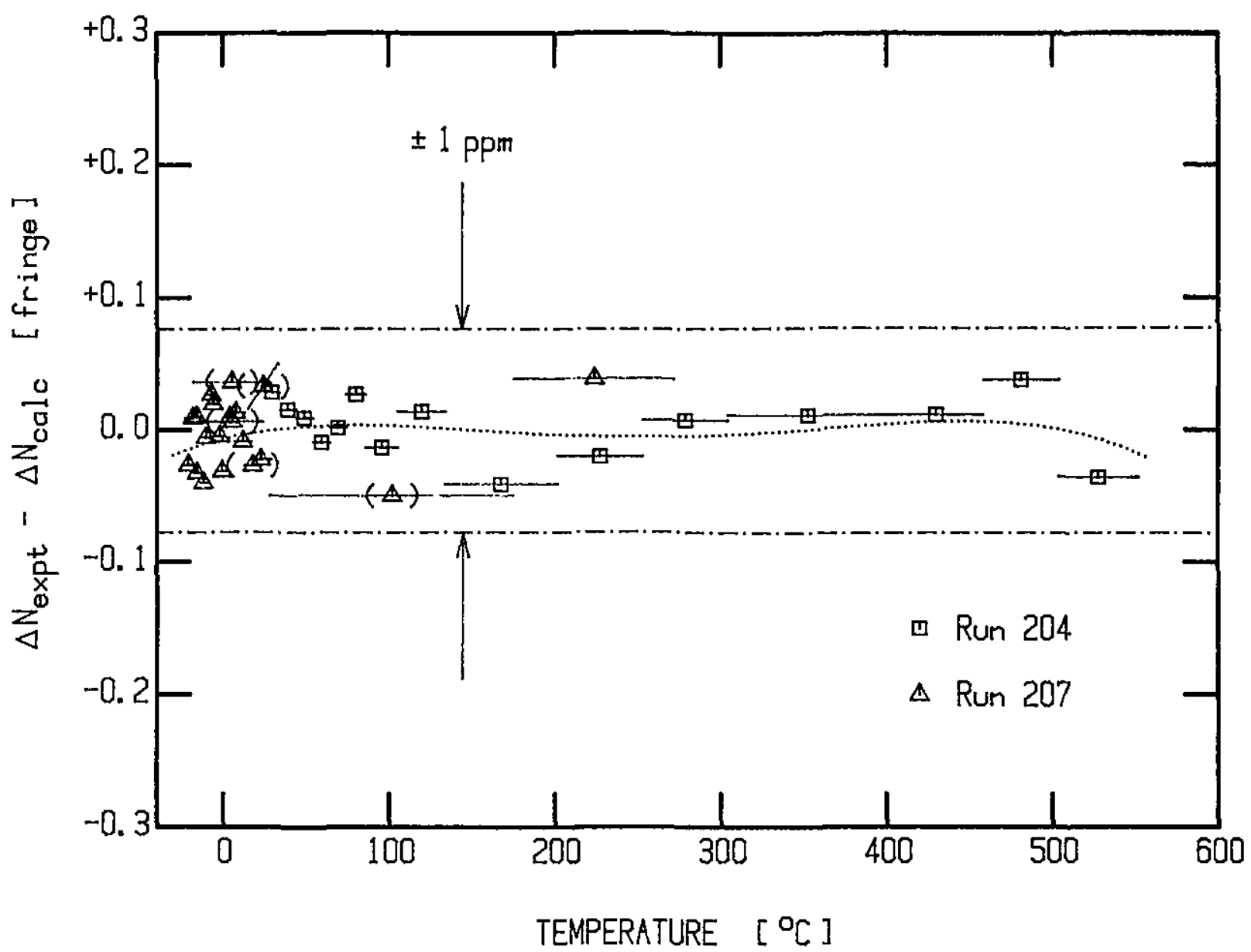

Figure 5-Differences in fringes of light at $546 \mathrm{~nm}$ between the length changes that were observed experimentally for ( $88 \mathrm{wt} \% \mathrm{Pt}+12$ $\mathrm{wt} \% \mathrm{Rh}$ ) and those that were calculated from the 4th degree fitting equation (see table 4). The squares indicate data of Run No. 204; the triangles, Run No. 207. The horizontal bar centered on each point denotes the temperature interval over which the length change was measured. () encloses a data point for which the whole number of fringes was estimated. / marks a data point that was given zero weight in the fitting process. $-. \ldots+\ldots$ indicates the bounds of one part per million in sample length. ….... indicates the difference between the five- and four-term fit to the experimental data.

columns 7 and 8 , respectively, of table 5. The column 8 differences are plotted against the average sample temperatures in figure 6.

We recommend that eqs (16) and (17) be used to calculate the percent linear thermal expansion for $(80 \mathrm{wt} \% \mathrm{Pt}+20 \mathrm{wt} \% \mathrm{Rh}$ ) for reference temperatures of $0{ }^{\circ} \mathrm{C}$ and $293 \mathrm{~K}$, respectively.

$$
\begin{aligned}
100 \epsilon\left(t, 0^{\circ} \mathrm{C}\right)= & 100 \sum_{n=1}^{4}\left[A_{n} / N\left(0^{\circ} \mathrm{C}\right)\right] t^{n} \\
= & 8.674 \times 10^{-4} t+2.538 \times 10^{-7} t^{2} \\
& \quad-2.081 \times 10^{-10} t^{3} \\
& +1.480 \times 10^{-13} t^{4}
\end{aligned}
$$

where $N\left(0^{\circ} \mathrm{C}\right)=78,269.81$ fringes and

$$
\begin{aligned}
100 \epsilon(T, 293 \mathrm{~K})= & -1.731 \times 10^{-2} \\
& +8.672 \times 10^{-4}(T-273.15) \\
& +2.538 \times 10^{-7}(T-273.15)^{2} \\
& -2.080 \times 10^{-10}(T-273.15)^{3} \\
& +1.480 \times 10^{-13}(T-273.15)^{4}
\end{aligned}
$$

\subsection{Effect of Alloying Upon the Thermal Expansion of $\mathbf{P t}$}

It is interesting to compare the temperature dependencies of the thermal expansion of the three samples studied in the course of this investigation to illustrate the effect of alloying pure platinum with rhodium. 


\section{Journal of Research of the National Bureau of Standards}

Table 5. Experimental data for ( $80 \mathrm{wt} \% \mathrm{Pt}+20 \mathrm{wt} \% \mathrm{Rh})$.

$N\left(21^{\circ} \mathrm{C}\right)=78,284.15 \pm 0.4$ fringes

\begin{tabular}{|c|c|c|c|c|c|c|c|}
\hline $\begin{array}{c}1 \\
\text { Point } \\
\text { No. }\end{array}$ & $t(68),{ }^{\circ} \mathrm{C}$ & F.F. ${ }^{\mathrm{a}}$ & $\begin{array}{c}\mathbf{4} \\
\text { Gas } \\
\text { Pressure } \\
\mathrm{kPa}\end{array}$ & $\begin{array}{l}\mathbf{5} \\
\text { F.F. } \\
\text { corr }\end{array}$ & $\Delta N_{\text {expt }}{ }^{\mathrm{b}}$ & $\Delta N_{\text {cale }}{ }^{e}$ & Dev, $\mathrm{fr}^{\mathrm{f}}$ \\
\hline \multicolumn{8}{|c|}{ Run 208} \\
\hline 1 & 231.678 & .371 & 0.27 & .367 & & & \\
\hline $1 a$ & & & & & -38.246 & -38.335 & .089 \\
\hline 2 & 180.153 & .126 & 0.27 & .121 & & & \\
\hline $2 a$ & & & & & $(82.564)^{\mathrm{c}}$ & 82.515 & .049 \\
\hline 3 & 290.002 & .691 & 0.40 & .685 & & & \\
\hline $3 a$ & & & & & -39.862 & -39.808 & -.054 \\
\hline 4 & 237.498 & .830 & 0.47 & .823 & & & \\
\hline $4 a$ & & & & & $(-80.325)$ & -80.288 & -.037 \\
\hline 5 & 128.691 & .502 & 0.20 & .498 & & & \\
\hline $5 a$ & & & & & -31.865 & -31.891 & .026 \\
\hline 6 & 84.160 & .639 & 0.27 & .633 & & & \\
\hline $6 a$ & & & & & 125.772 & 125.762 & .010 \\
\hline 7 & 255.511 & .409 & 0.27 & .405 & & & \\
\hline $7 a$ & & & & & $(-199.679)$ & -199.723 & .044 \\
\hline 8 & -23.001 & .735 & 0.27 & .726 & & & \\
\hline $8 a$ & & & & & 3.779 & 3.784 & -.005 \\
\hline 9 & -17.359 & .513 & 0.27 & .505 & & & \\
\hline $9 a$ & & & & & $(-0.013)^{\mathrm{d}}$ & -0.009 & -.004 \\
\hline 10 & -17.372 & .500 & 0.27 & .492 & & & \\
\hline $10 a$ & & & & & 3.980 & 3.936 & .044 \\
\hline 11 & -11.524 & .480 & 0.27 & .472 & & & \\
\hline $11 a$ & & & & & 3.243 & 3.246 & -.003 \\
\hline 12 & -6.717 & .723 & 0.27 & .715 & & & \\
\hline $12 a$ & & & & & $(0.011)^{\mathrm{d}}$ & .080 & -.069 \\
\hline 13 & -6.599 & .734 & 0.27 & .726 & & & \\
\hline $13 a$ & & & & & 5.691 & 5.695 & -.004 \\
\hline 14 & 1.802 & .425 & 0.27 & .417 & & & \\
\hline $14 a$ & & & & & 6.902 & 6.880 & .022 \\
\hline 15 & 11.896 & .327 & 0.27 & .319 & & & \\
\hline $15 a$ & & & & & 9.869 & 9.857 & .012 \\
\hline 16 & 26.258 & .195 & 0.27 & .188 & & & \\
\hline $16 a$ & & & & & $(0.337)^{\mathrm{d}}$ & 0.355 & .018 \\
\hline 17 & 26.773 & .536 & 0.40 & .525 & & & \\
\hline $17 a$ & & & & & 16.906 & 16.799 & .107 \\
\hline 18 & 50.993 & .438 & 0.27 & .431 & & & \\
\hline $18 a$ & & & & & 45.797 & 45.727 & .070 \\
\hline 19 & 115.513 & .234 & 0.27 & .228 & & & \\
\hline $19 a$ & & & & & 46.184 & 46.160 & .024 \\
\hline 20 & 178.903 & .417 & 0.27 & .412 & & & \\
\hline $20 a$ & & & & & 44.227 & 44.256 & -.029 \\
\hline 21 & 238.332 & .645 & 0.40 & .639 & & & \\
\hline $21 a$ & & & & & 46.778 & 46.841 & -.063 \\
\hline 22 & 300.008 & .423 & 0.40 & .417 & & & \\
\hline $22 a$ & & & & & 40.151 & 40.153 & -.002 \\
\hline 23 & 351.982 & .573 & 0.40 & .568 & & & \\
\hline $23 a$ & & & & & 81.957 & 81.955 & .002 \\
\hline 24 & 455.685 & .529 & 0.40 & .525 & & & \\
\hline $24 a$ & & & & & 36.923 & 36.897 & .026 \\
\hline 25 & 501.350 & .454 & 0.53 & .448 & & & \\
\hline $25 a$ & & & & & 39.649 & 39.668 & -.019 \\
\hline 26 & 549.719 & .102 & 0.53 & .097 & & & \\
\hline
\end{tabular}

a F.F.; fractional fringe count at the fiducial mark.

b $\Delta N_{\text {expt }}$; corrected differences in sample length, expressed in fringes.

c Use of parentheses indicates that the integral number of fringes passing the fiducial mark during a particular temperature change was obtained from a trial plot of $\Delta \mathrm{N} / \Delta \mathrm{t}$ vs the mean temperature of the interval (see section 2.7 ).

${ }^{d}$ Data points $9 \mathrm{a}, 12 \mathrm{a}$, and $16 \mathrm{a}$ were given zero weight in the fitting procedure.

e $\Delta N_{\text {calc }}$; fringe differences calculated for the end-point temperatures given in column 2, using eq (8) with the coefficients given in table 6.

' Dev; $\Delta N_{\text {expt }}-\Delta N_{\text {calc }}$. These differences are plotted against the average experimental end-point temperatures in figure 6. 


\section{Journal of Research of the National Bureau of Standards}

In table 7, we present values for the percent linear thermal expansion, $100 \epsilon\left(t, 0^{\circ} \mathrm{C}\right)$, for each of the three samples. These values were calculated using eqs (12), (14), and (16).

The differences between the values of the thermal expansion for the two alloys and those for pure platinum are plotted against temperature in figure 7.

Substitution of rhodium into the platinum lattice progressively reduces the thermal expansion in the temperature range $0{ }^{\circ} \mathrm{C}$ to $350^{\circ} \mathrm{C}$, then causes it to increase. This effect is made more noticeable as one examines the coefficient of thermal expansion. Values of this quantity are presented in table 8 . The values were obtained by differentiating eqs (12), (14), and (16).

The values for the coefficient of linear thermal expansion are plotted against Celsius temperature

Table 6. Fitting parameters for the thermal expansion of (80 wt \% Pt $+20 w t \% R h)$.

Equation used in least-squares fitting procedure:

$$
\Delta N\left(t_{i}, t_{i+1}\right)=\sum_{n=1}^{n t} A_{n}\left(t^{n}{ }_{i}-t^{n}{ }_{i+1}\right)
$$

Determination of number of polynomial terms $m$ for "best fit": $\mathrm{p}=22$ data points

\begin{tabular}{|c|c|c|c|}
\hline$m$ & $\sigma^{a}$ & $F_{m}{ }^{b}$ & $F_{0.95}(1, p-m)$ \\
\hline 1 & 2.2168 & & \\
\hline 2 & 0.1760 & 3783.4 & 4.35 \\
\hline 3 & 0.0871 & 72.0 & 4.38 \\
\hline 4 & 0.0486 & 49.6 & 4.41 \\
\hline 5 & 0.0489 & 0.8 & 4.45 \\
\hline 6 & 0.0496 & 0.2 & 4.49 \\
\hline
\end{tabular}

Coefficients of 4 th degree polynomial:

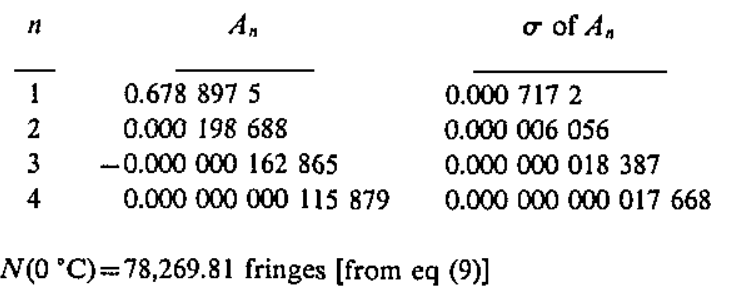

$\sigma$; the estimated standard deviation of the fit.

b $F_{m}$; an index used to estimate the level of significance of the $m$ th coefficient in the equation fitted to the data.

$$
F_{m}=1+(p-m+1)\left[\left(\frac{\sigma_{m-1}}{\sigma^{m}}\right)^{2}-1\right]
$$

where $p$ is the number of data points and $m$ is the number of coefficients in the polynomial. The coefficient $A_{m}$ is considered significant at the desired level of confidence if $F_{m}$ is greater than the corresponding value given in the fourth column. (Entries in column 4 were taken from a standard table for the $F$-distribution, e.g., table III of [22].) in figure 8 . The curves show the initial reduction of the coefficient at $0^{\circ} \mathrm{C}$, and the progressive increase at higher temperatures in the range that was studied in this investigation.

Table 7. Values of the percent linear thermal expansion relative to $0{ }^{\circ} \mathrm{C}$ for $100 \% \mathrm{Pt}$ and alloys of $(88 \mathrm{wt} \% \mathrm{Pt}+12 \mathrm{wt} \% \mathrm{Rh})$ and ( $80 \mathrm{wt} \% \mathrm{Pt}+20 \mathrm{wt} \% \mathrm{Rh}$ ) calculated from eqs (12), (14), and (16), respectively.

\begin{tabular}{rccc}
\hline \multirow{2}{*}{$t$} & \multicolumn{3}{c}{$100 \epsilon\left(t, 0^{\circ} \mathrm{C}\right)=100\left[L(t) / L\left(0^{\circ} \mathrm{C}\right)-1\right]$} \\
\cline { 2 - 4 }${ }^{\circ} \mathrm{C}$ & & $\begin{array}{c}88 \mathrm{wt} \% \mathrm{Pt}+ \\
12 \mathrm{wt} \% \mathrm{Rh} \\
\mathrm{Eq} \mathrm{(14)}\end{array}$ & $\begin{array}{c}80 \mathrm{wt} \% \mathrm{Pt}+ \\
20 \mathrm{wt} \% \mathrm{Rh} \\
\mathrm{Eq}(16)\end{array}$ \\
\hline-20 & -0.0177 & -0.0174 & -0.0172 \\
0 & 0 & 0 & 0 \\
20 & 0.0178 & 0.0176 & 0.0174 \\
50 & 0.0447 & 0.0443 & 0.0440 \\
100 & 0.0903 & 0.0896 & 0.0891 \\
& & & 0.1352 \\
150 & 0.1365 & 0.1358 & 0.1822 \\
200 & 0.1835 & 0.1827 & 0.2300 \\
250 & 0.2311 & 0.2304 & 0.2786 \\
300 & 0.2793 & 0.2788 & 0.3280 \\
350 & 0.3282 & 0.3279 & 0.3780 \\
400 & 0.3776 & 0.3777 & 0.4288 \\
450 & 0.4277 & 0.4282 & 0.4804 \\
500 & 0.4784 & 0.4793 & 0.5328 \\
550 & 0.5298 & 0.5313 & \\
\hline
\end{tabular}

Table 8. Values of the coefficient of linear thermal expansion for $100 \% \mathrm{Pt}$ and alloys of ( $88 \mathrm{wt} \% \mathrm{Pt}+12 \mathrm{wt} \% \mathrm{Rh})$ and (80 wt\% $\mathrm{Pt}+20 \mathrm{wt} \% \mathrm{Rh}$ ) calculated from the temperature

\begin{tabular}{|c|c|c|c|}
\hline \multirow[t]{2}{*}{$t$} & \multicolumn{3}{|c|}{$10^{6} a\left(t, 0^{\circ} \mathrm{C}\right)=10^{6} \mathrm{~d} L(t) / \mathrm{d} t / L\left(0^{\circ} \mathrm{C}\right)$} \\
\hline & $\begin{array}{c}100 \% \mathrm{Pt} \\
(\mathrm{d} / \mathrm{d} t) \mathrm{Eq}(12)\end{array}$ & $\begin{array}{c}88 \mathrm{wt} \% \mathrm{Pt}+ \\
12 \mathrm{wt} \% \mathrm{Rh} \\
(\mathrm{d} / \mathrm{d} t) \mathrm{Eq}(14)\end{array}$ & $\begin{array}{c}80 \text { wt\% Pt+ } \\
20 \text { wt\% Rh } \\
(\mathrm{d} / \mathrm{d} t) \text { Eq }(16)\end{array}$ \\
\hline${ }^{\circ} \mathrm{C}$ & ${ }^{\circ} \mathrm{C}^{-1}$ & ${ }^{\circ} \mathrm{C}^{-1}$ & ${ }^{\circ} \mathrm{C}^{-1}$ \\
\hline-20 & 8.790 & 8.677 & 8.570 \\
\hline 0 & 8.862 & 8.763 & 8.674 \\
\hline 20 & 8.931 & 8.846 & 8.773 \\
\hline 50 & 9.029 & 8.964 & 8.913 \\
\hline 100 & 9.183 & 9.147 & 9.125 \\
\hline 150 & 9.324 & 9.314 & 9.315 \\
\hline 200 & 9.457 & 9.468 & 9.487 \\
\hline 250 & 9.583 & 9.613 & 9.645 \\
\hline 300 & 9.705 & 9.752 & 9.795 \\
\hline 350 & 9.826 & 9.888 & 9.940 \\
\hline 400 & 9.949 & 10.023 & 10.085 \\
\hline 450 & 10.076 & 10.162 & 10.234 \\
\hline 500 & 10.210 & 10.306 & 10.392 \\
\hline 550 & 10.354 & 10.460 & 10.563 \\
\hline
\end{tabular}
derivatives of eqs (12), (14), and (16), respectively. 


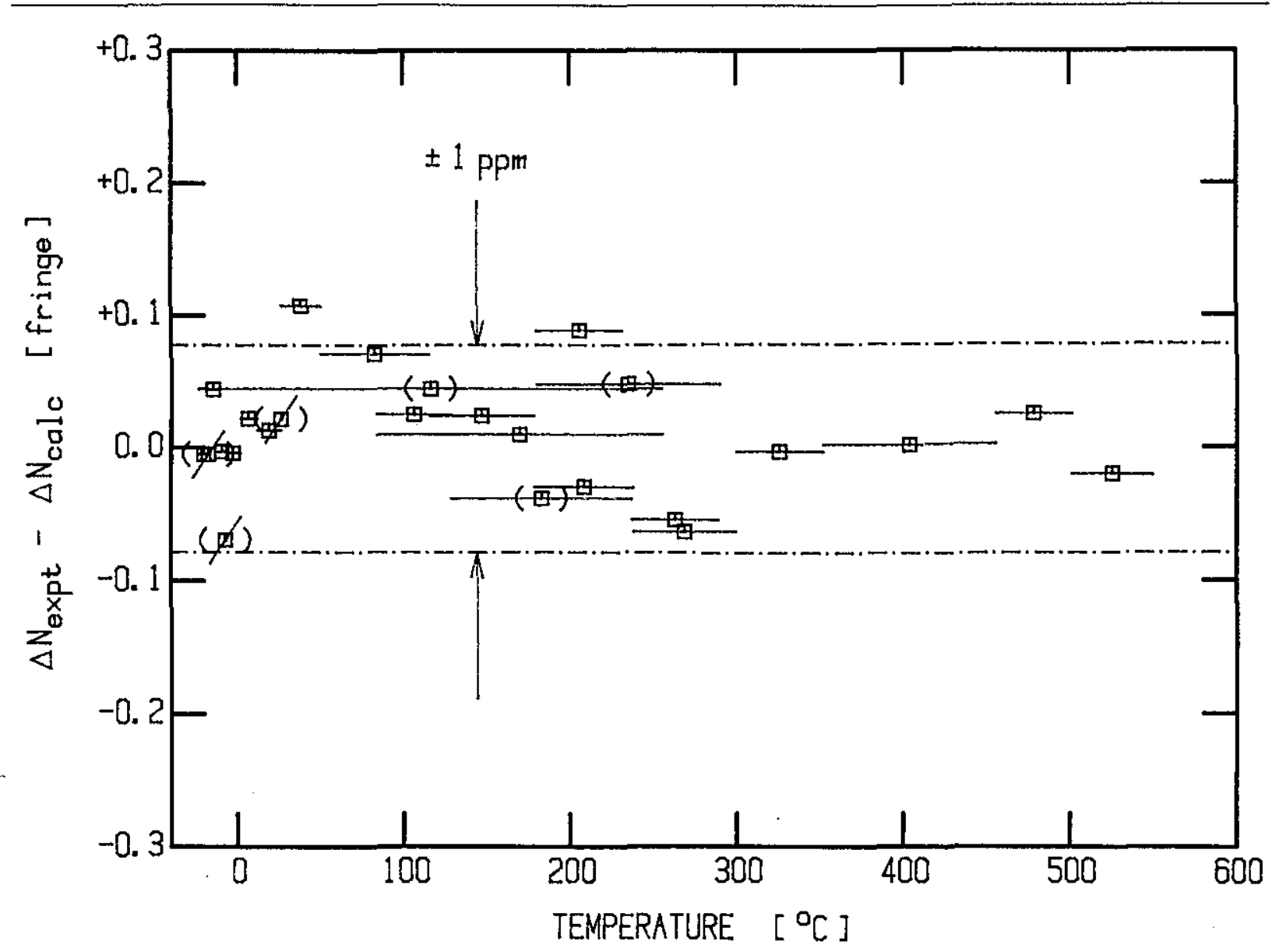

Figure 6-Differences in fringes of light at $546 \mathrm{~nm}$ between the length changes that were observed experimentally for $(80 \mathrm{wt} \% \mathrm{Pt}+20$ wt \% Rh) and those that were calculated from the 4th degree fitting equation (see table 6). The horizontal bar centered on each point denotes the temperature interval over which the length change was measured. () encloses a data point for which the whole number of fringes was estimated. / marks a data point that was given zero weight in the fitting process. _.. _ _ indicates the bounds of one part per million in sample length.

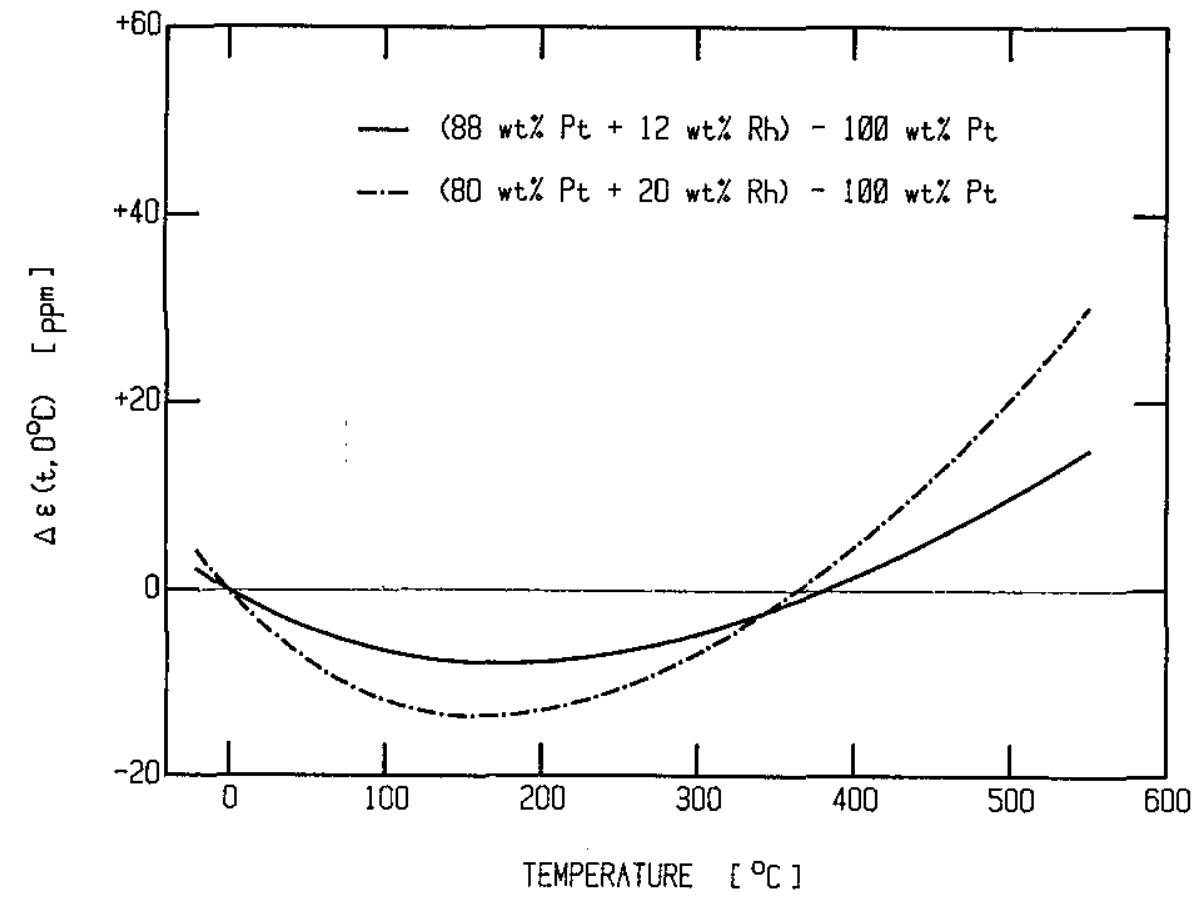

Figure 7-Differences in linear thermal expansion, $\epsilon\left(t, 0^{\circ} \mathrm{C}\right)$ between the (88 wt\% Pt+12 wt\% $\mathrm{Rh})$ or the ( $80 \mathrm{wt} \% \mathrm{Pt}+20$ wt\% $\mathrm{Rh}$ ) sample and the $100 \%$ Pt sample, as calculated from the respective fitting eqs (14), (16), and (12). 


\section{Journal of Research of the National Bureau of Standards}

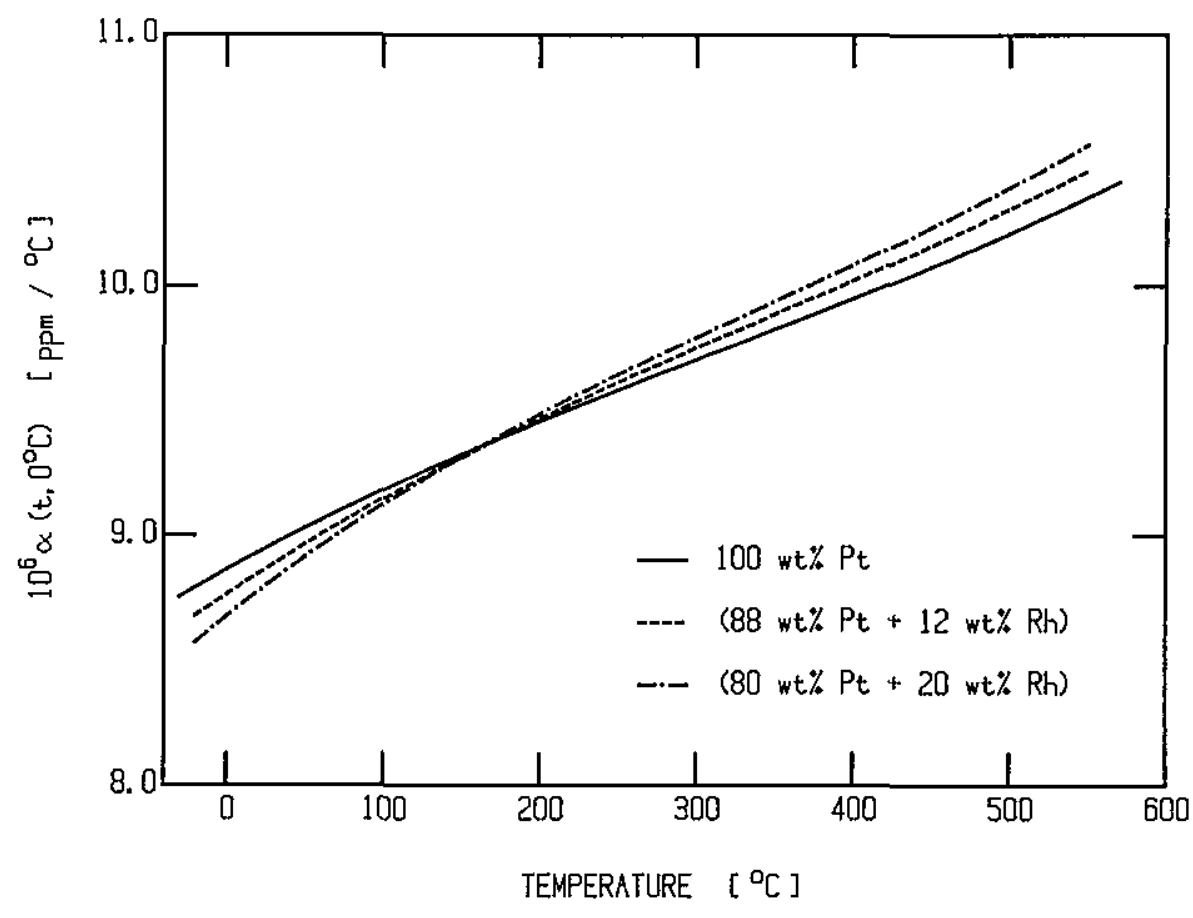

Figure 8-Coefficient of linear thermal expansion $\alpha\left(t, 0^{\circ} \mathrm{C}\right)$ for $100 \% \mathrm{Pt}$, for $(88 \mathrm{wt} \% \mathrm{Pt}+12$ $\mathrm{wt} \% \mathrm{Rh}$ ), and for ( $80 \mathrm{wt} \%$ $\mathrm{Pt}+20 \mathrm{wt} \% \mathrm{Rh})$. The curves were obtained by differentiating, respectively, eqs (12), (14), and (16).

\section{Measurement Uncertainties \\ 4.1 Random Uncertainties}

The Merritt-Saunders method for the determination of the thermal expansion appears to provide length measurements with an overall uncertainty of 0.1 fringe or less, a value that corresponds to about $1 \mathrm{ppm}$ of our sample length. The level of our overall experimental imprecision is made clear by the process of fitting the thermal expansion data for each sample (tables 2, 4, and 6) with a simple power series. Although the resolution of the fringecounting procedure is \pm 0.001 fringe, we estimate that the imprecision involved in the use of the microdensitometer to determine the fractional fringe count (col. 3 of tables 1, 3, and 5) may be 10 times as great. The determination of temperature was accomplished with relatively good precision; the thermometer sensor/bridge system used in this work allowed us to resolve temperature within $\pm 0.001{ }^{\circ} \mathrm{C}$ throughout the range of the measurements.

Another possible source of random error in our experiment is the occurrence of undetected mechanical disturbances of the apparatus during the several weeks required for the measurements. Such disturbances might lead to small displacements of the optical system and thus to incorrect values of the sample length changes.

\subsection{Systematic Uncertainties}

There are several potential sources of systematic error in this experiment. The fact that the uncertainties attached to predicted data points in the fitting procedures are relatively large compared to the resolution of the sample length and of the sample temperature, as we noted above, must be ascribed either to the random disturbances mentioned above or to the presence of one or more systematic errors.

Effects contributing to systematic error in the measured sample temperature include the following:

a) Self-heating of the platinum resistance thermometer;

b) Inadequate thermal tempering of the PRT;

c) Drift in the calibration of the PRT or of the bridge that was used in its measurement;

d) Temperature gradients within the sample block;

e) Deviation of the sample temperature from the block temperature, arising from convective or radiative effects within the sample chamber.

Efforts were undertaken to assign limits to all of the errors listed above, either on the basis of calculations or on the basis of separate experiments conducted during this study. What follows is our estimate of these limits:

a) Self-heating. We used a measuring current of 1 $\mathrm{mA}$ through our PRT $\left(2.5 \mathrm{ohms}\right.$ at $\left.0{ }^{\circ} \mathrm{C}\right)$. In no 
case did the temperature error due to self-heating exceed $0.0002{ }^{\circ} \mathrm{C}$.

b) Quality of thermal tempering of the PRT. This problem caused considerable concern in the planning stage of the experiment. To help evaluate the thermal tempering, we installed a special heater-a helical coil about $6 \mathrm{~cm}$ long-on the guide tube that receives the PRT where it intersects shell I1. Introduction of moderate power to this heater had no discernible effect upon the measured temperature of the thermometer, leading us to conclude that the thermometer tempering was adequate.

c) Thermometer or bridge calibration drift. Periodic measurement of a standard resistor allowed us to conclude that the temperature error due to drift in calibration of the resistance bridge did not exceed $0.00011^{\circ} \mathrm{C}$, a negligible level. Similarily, periodic re-calibration of the PRT showed it to be stable within $0.001^{\circ} \mathrm{C}$.

d) Temperature gradients in the sample block. A scan was made of the vertical gradient in the sample block (I3 in fig. 1) by withdrawing the thermometer $1 \mathrm{~cm}$ at a time through its static seal. To do this it was necessary to maintain a pressure of $101 \mathrm{kPa}$ pressure of helium gas in the apparatus. The maximum gradient observed under these conditions was $0.02{ }^{\circ} \mathrm{C} / \mathrm{cm}$. Under the usual measuring conditions, wherein the gas pressure did not exceed $1.5 \mathrm{kPa}$, we estimate the thermal gradient as less than $0.001{ }^{\circ} \mathrm{C} / \mathrm{cm}$.

e) Sample gradients arising from convective or radiative effects. Heat transfer calculations indicate that the temperature difference between the sample and its enclosure arising from convective or radiative effects did not exceed $0.001{ }^{\circ} \mathrm{C}$. No experimental verification of this result was attempted.

Another systematic error in the Merritt-Saunders experiment can arise from differences in the thermal expansions of the sample and of the glass plates that touch it. It is likely that the contact between the glass plates $A$ and $B$ and the sample pads $a-a, b-b$, and $c-c$ takes place at different points during the measurement process. Given the thermal expansion rates of the two materials and the sample geometry, one can expect the relative separation of the points of contact on each plate to change by about $6.5 \mu \mathrm{m}$ as the system temperature varies from $-20^{\circ} \mathrm{C}$ to $560^{\circ} \mathrm{C}$. While this motion corresponds to a change in angle of the upper plate of only 2.5 microdegrees and thus to a shift in the fringe count at the fiducial mark of only 0.002 fringe, if the motion were to take place in a hysteretic and erratic fashion, then the fringe pattern could be disturbed to a larger extent.
Systematic errors can arise from incorrect measurement of the filling-gas pressure or from outgassing within the sample chamber during the measurements, from incorrect evaluation of the wavelength of the radiation used to form the fringe pattern, from use of incorrect values of the refractive index of the filling gas as given by eq (3), and from variation in developing or handling the film. All of these would appear to be relatively small with respect to the imprecision found in the fitting procedure. The uncertainty in the determination of the reference lengths of the samples is $30 \mathrm{ppm}$, approximately $10 \mathrm{ppm}$ of that quantity arising from uncertainty in the reading of the dial micrometer and $20 \mathrm{ppm}$ owing to uncertainty in the temperature of the samples and gage blocks; an overall bias in the sample length at this level, however, has only a negligible effect on the calculated values of the thermal expansion.

Yet another systematic error can arise from changes in the sample properties during the measurements. Barter and Darling [23] have illustrated the drift in the thermal expansion of an $(80 \mathrm{wt} \%$ $\mathrm{Pt}+20 \mathrm{wt} \% \mathrm{Rh}$ ) sample that accompanies the first heating of a hard-drawn material to its annealing temperature. Hahn and Kirby [24], on the other hand, have reported that subsequent measurements of annealed samples of Pt showed no perceptible drift in the thermal expansion. We took care to anneal our samples prior to measurement, so that we expect only negligible error from this source.

In table 9, we summarize our estimates of the uncertainties arising in the present experiment.

Table 9. Uncertainties in Merritt-Saunders thermal expansion measurements.

\section{A. Random}

1. Overall experimental uncertainty (from fitting procedure) $<1 \mathrm{ppm}$ of sample length.

2. Uncertainty of fringe measurement \pm 0.01 fringes.

3. Sample temperature resolution $\pm 0.001{ }^{\circ} \mathrm{C}$.

4. Mechanical shock to optical system during measurement-unknown magnitude.

\section{B. Systematic}

1. Sample temperature different from measured temperature $<0.001^{\circ} \mathrm{C}$.

2. Fringe count error $-<0.01$ fringe.

3. Refractive index of medium incorrect $-<0.02$ fringe.

4. Error in interferometer wavelength $-<1 \mathrm{ppm}$.

5. Film and reader irregularities-negligible.

6. Sample property changes during measurements-unknown. 


\section{Comparison With Other Results}

High-purity platinum serves as a standard for thermal expansion measurements. Therefore it seems very useful to compare high-precision measurements on this material that originate in different laboratories.

Numerous workers have studied the thermal expansion of Pt and Pt-Rh alloys. Nearly all of the results published prior to 1975 have been compiled by Kirby and others in the form of graphs and tables of coefficient of linear thermal expansion, $\alpha(T, 293 \mathrm{~K})=[1 / L(293 \mathrm{~K})][\mathrm{d} L(T) / \mathrm{d} T]$, and percent linear thermal expansion relative to $293 \mathrm{~K}, 100$ $\epsilon(T, 293 \mathrm{~K})=100[L(T)-L(293 \mathrm{~K})] /[L(293 \mathrm{~K})]$ [4].

In analyzing our data, we have attempted to use the most direct fitting process available, that is, one in which the experimentally determined sample length changes were fitted by a polynomial consisting of differences of increasing powers of the endpoint temperatures [eq (8)]. By applying the F-test for evaluating the significance of the coefficients, we attempted to avoid problems that can arise from "over-fitting" experimental data (i.e., using polynomial functions of higher degree than justified by the precision of the data).

We remind the reader that a wide variation exists in the manner of expression of thermal expansion results, and that careless use of these expressions can lead to discrepancies among similar data [25]. Any of the customary forms for the expression of thermal expansion that are found in the literature, including

$$
\frac{L(t)-L\left(t_{\mathrm{ref}}\right)}{L\left(t_{\mathrm{ref}}\right)\left(t-t_{\mathrm{ref}}\right)} \quad \begin{gathered}
\text { ("average thermal expansiv- } \\
\text { ity") }
\end{gathered}
$$

$\frac{L(t+\mathrm{d} t)-L(t-\mathrm{d} t)}{L\left(t_{\mathrm{ret}}\right) 2 \mathrm{~d} t}$ ("thermal expansivity")

$\frac{L(t+\mathrm{d} t)-L(t-\mathrm{d} t)}{L(t) 2 \mathrm{~d} t} \quad \begin{gathered}\text { ("instantaneous thermal ex- } \\ \text { pansivity") }\end{gathered}$

$\frac{L(t)}{L\left(t_{\mathrm{ref}}\right)} \quad$ ("linear thermal expansion")

$\frac{100\left[L(t)-L\left(t_{\mathrm{ref}}\right)\right]}{L\left(t_{\mathrm{ref}}\right)} \quad \begin{gathered}\text { ("percent linear thermal ex- } \\ \text { pansion") }\end{gathered}$

can be derived directly from fitting equations such as eq (8).

\section{$5.1100 \% \mathrm{Pt}$}

Twenty-eight sets of data for the linear thermal expansion of $100 \% \mathrm{Pt}$ have been critically analyzed by the Thermophysical Properties Research Center (TPRC) with the result that a "recommended curve" for the percent linear thermal expansion over the range $293 \mathrm{~K}$ to $1900 \mathrm{~K}$ has been offered [5]

$$
\begin{aligned}
100 \epsilon(T, 293 \mathrm{~K})= & 9.122 \times 10^{-4}(T-293) \\
& +7.467 \times 10^{-8}(T-293)^{2} \\
& +4.258 \times 10^{-11}(T-293)^{3} .
\end{aligned}
$$

Note that temperature in eq (18) is expressed in kelvins; we denote these temperatures by $T$. At selected temperatures TPRC also tabulated "recommended values" for this quantity which differ slightly from those given by eq (18).

The recent study by Hahn and Kirby [24] and the older work by Holborn and Day [26] most nearly approximate our own work in experimental technique, temperature range, and precision. Hahn and Kirby represented their results for the percent linear thermal expansion of $100 \% \mathrm{Pt}$ for the temperature range 293 to $1900 \mathrm{~K}$ by the relation

$$
\begin{aligned}
100 \epsilon(T, 293 \mathrm{~K})= & 0.2279+6.117 \times 10^{-4} T \\
& +8.251 \times 10^{-7} T^{2} \\
& -1.1187 \times 10^{-9} T^{3} \\
& +9.1523 \times 10^{-13} T^{4} \\
& -3.6754 \times 10^{-16} T^{5} \\
& +5.893 \times 10^{-20} T^{6} .
\end{aligned}
$$

Holborn and Day expressed their results as an equation in degrees Celsius for the coefficient of linear thermal expansion. Their integrated equation referenced to $293 \mathrm{~K}$ is

$$
\begin{aligned}
100 \epsilon(T, 293 \mathrm{~K})= & -0.0176 \\
& +8.866 \times 10^{-4} \times(T-273.15) \\
& +1.322 \times 10^{-7} \times(T-273.15)^{2} .
\end{aligned}
$$

In table 10 , values of the percent linear expansion relative to $293 \mathrm{~K}$ as calculated from eqs (18) to (20) plus TPRC recommended values for specific temperatures are compared to values calculated 
Table 10. Values of the percent linear thermal expansion relative to $293 \mathrm{~K}$ for $100 \% \mathrm{Pt}$ from various selected sources.

\begin{tabular}{cccccc}
\hline \hline$T$ & \multicolumn{5}{c}{$100 \epsilon(T, 293 \mathrm{~K})=100[L(T) / L(293 \mathrm{~K})-1]$} \\
\cline { 2 - 6 } $\mathrm{K}$ & $\begin{array}{c}\text { This work } \\
\text { Eq (12) }\end{array}$ & $\begin{array}{c}\text { TPRC [5] } \\
\text { recommended } \\
\text { value }\end{array}$ & $\begin{array}{c}\text { Hahn and } \\
\text { Eq (18) } \\
\text { Kq }\end{array}$ & $\begin{array}{c}\text { Holborn and } \\
\text { Eq (19) }\end{array}$ & $\begin{array}{c}\text { Day [26] } \\
\text { Eq (20) }\end{array}$ \\
\hline 273.15 & -0.0177 & & & & -0.0177 \\
293 & 0 & 0 & 0 & 0 & 0 \\
300 & 0.0063 & & 0.0064 & 0.0062 & 0.0062 \\
400 & 0.0974 & 0.096 & 0.0985 & 0.0971 & 0.0969 \\
500 & 0.1913 & 0.189 & 0.1924 & 0.1910 & 0.1903 \\
600 & 0.2878 & 0.288 & 0.2883 & 0.2873 & 0.2863 \\
700 & 0.3867 & 0.388 & 0.3865 & 0.3858 & 0.3849 \\
800 & 0.4881 & 0.490 & 0.4872 & 0.4866 & 0.4862 \\
\hline
\end{tabular}

from eq (13). Curves showing the differences between eqs (18) to (20) and our values are plotted against degrees Celsius in figure 9. The differences are generally larger than the total uncertainty in our values which we believe to be less than $1 \mathrm{ppm}$.

\section{$5.2(88$ wt $\%$ Pt +12 wt $\%$ Rh) Alloy}

No other thermal expansion data were found for the (88 wt\% Pt $+12 w t \% \mathrm{Rh})$ alloy. Ebert [28] has published values for the thermal expansion relative to $0{ }^{\circ} \mathrm{C}$ of pure $\mathrm{Rh}$ which indicate an uncertainty of about $10 \mathrm{ppm}$. Using the Ebert data combined with our values for $100 \% \mathrm{Pt}$ we have estimated the thermal expansion of the ( $88 \mathrm{wt} \% \mathrm{Pt}+12 \mathrm{wt} \% \mathrm{Rh})$ alloy as

$$
\begin{aligned}
\epsilon\left(t, 0{ }^{\circ} \mathrm{C}\right)_{\mathrm{Pt}_{(1-x)}-\mathrm{Rh}_{\mathrm{x}}}= & (1-x) \epsilon\left(t, 0^{\circ} \mathrm{C}\right)_{\mathrm{P}_{\mathrm{t}}} \\
& +x \epsilon\left(t, 0^{\circ} \mathrm{C}\right)_{\mathrm{Rh}}
\end{aligned}
$$

where $x=0.12$. The resulting values are given in table 11 together with those for $100 \% \mathrm{Pt}$ given by eq (12) and for $100 \% \mathrm{Rh}$ as reported by Ebert. The values for the thermal expansion of alloy as estimated in this manner are all within $10 \mathrm{ppm}$ of our results.

Table 11. Values of the percent linear thermal expansion relative to $0^{\circ} \mathrm{C}$ for the ( $88 \mathrm{wt} \% \mathrm{Pt}+12 \mathrm{wt} \% \mathrm{Rh}$ ) alloy [eq (14)]

\begin{tabular}{|c|c|c|c|c|}
\hline \multirow{3}{*}{$\begin{array}{c}t \\
{ }^{\circ} \mathrm{C}\end{array}$} & \multicolumn{4}{|c|}{$100 \epsilon\left(t, 0^{\circ} \mathrm{C}\right)=100\left[L(t) / L\left(0^{\circ} \mathrm{C}\right)-1\right]$} \\
\hline & \multirow[b]{2}{*}{$\begin{array}{c}100 \% \mathrm{Pt} \\
\mathrm{Eq}(12)\end{array}$} & \multirow[b]{2}{*}{$\begin{array}{c}100 \% \mathrm{Rh} \\
{[28]}\end{array}$} & \multicolumn{2}{|c|}{$88 w t \% \mathrm{Pt}+12 \mathrm{wt} \% \mathrm{Rh}$} \\
\hline & & & $\begin{array}{c}\text { This work } \\
\text { Eq (14) }\end{array}$ & $\begin{array}{c}\text { Estimated } \\
\text { Eq (21) }\end{array}$ \\
\hline 0 & 0 & 0 & 0 & 0 \\
\hline 50 & 0.0447 & 0.040 & 0.0443 & 0.0441 \\
\hline 100 & 0.0903 & 0.085 & 0.0896 & 0.0899 \\
\hline 200 & 0.1835 & 0.180 & 0.1827 & 0.1831 \\
\hline 300 & 0.2793 & 0.280 & 0.2788 & 0.2794 \\
\hline 400 & 0.3776 & 0.385 & 0.3777 & 0.3785 \\
\hline 500 & 0.4784 & 0.490 & 0.4793 & 0.4798 \\
\hline
\end{tabular}
compared with those estimated using eq (21) with $x=0.12$.

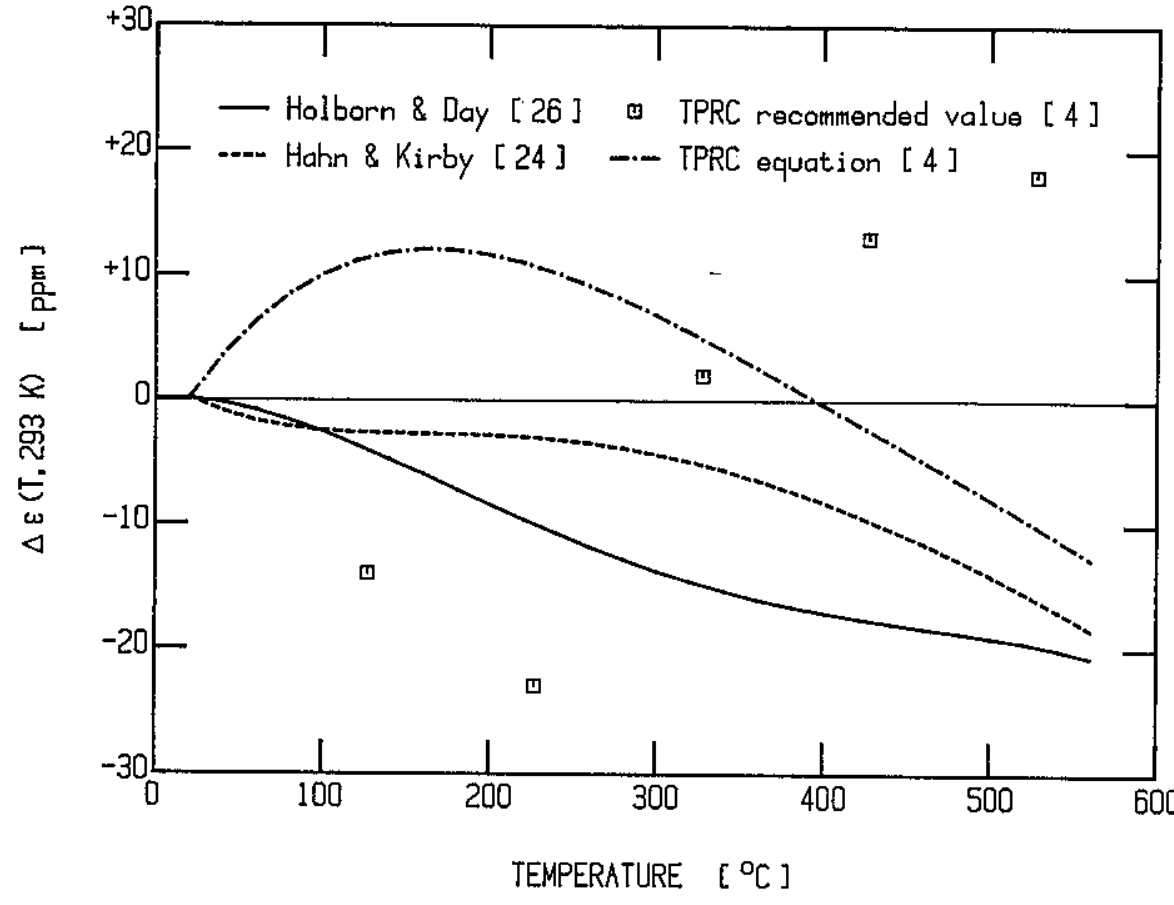

Figure 9-The differences between various published representations for the linear thermal expansion of $100 \% \mathrm{Pt}$ and that obtained in this research. 


\section{$5.3(80 w t \% \mathbf{P t}+20 w t \% \mathbf{R h})$ Alloy}

The linear thermal expansion of the $(80 \mathrm{wt} \%$ $\mathrm{Pt}+20 \mathrm{wt} \% \mathrm{Rh}$ ) alloy has also been measured by Day and Sosman [27] and by Barter and Darling [23].

Day and Sosman represented their measurements as an equation for the coefficient of linear thermal expansion referenced to $0^{\circ} \mathrm{C}$. The integral of their equation, expressed as percent linear thermal expansion is

$$
\begin{aligned}
100 \epsilon\left(t, 0^{\circ} \mathrm{C}\right)= & 8.79 \times 10^{-4} t \\
& +1.61 \times 10^{-7} t^{2} .
\end{aligned}
$$

Once again we have estimated the percent linear thermal expansion of the (80 wt\% Pt $+20 \mathrm{wt} \% \mathrm{Rh})$ alloy using the data of Ebert for $100 \% \mathrm{Rh}$ and our values for $100 \% \mathrm{Pt}$ combined according to eq (21) with $x=0.20$. The resulting values are given in table 12 together with values representative of the Day and Sosman measurements as calculated by eq (22) and the results given by Barter and Darling. The relationship between these quantities is plotted against degrees Celsius in figure 10 with the smooth curve indicating the difference between eq (22) and eq (16). Note that the differences between thermal expansion values calculated from eq (16) and the results of Barter and Darling are plotted at $1 / 10$ scale. The close agreement between the values estimated from eq (21) and our results, for both the $12 \%$ and the $20 \% \mathrm{Rh}$ alloy, as well as the close agreement between our results and those of Day and Sosman, indicate that significant systematic error may exist in the Barter and Darling experimental results.

Table 12. Values of the percent linear thermal expansion relative to $0{ }^{\circ} \mathrm{C}$ for the $(80 \mathrm{wt} \% \mathrm{Pt}+20 \mathrm{wt} \% \mathrm{Rh})$ alloy from various sources including those estimated using eq (21) with $x=0.20$.

\begin{tabular}{rlccc}
\hline$t$ & \multicolumn{4}{c}{$100 \in\left(t, 0^{\circ} \mathrm{C}\right)=100\left[L(t) / L\left(0^{\circ} \mathrm{C}\right)-1\right]$} \\
\cline { 2 - 5 } & $\begin{array}{c}\text { Day and } \\
\text { Sosman } \\
\text { Eq (22) }\end{array}$ & $\begin{array}{c}\text { Barter and } \\
\text { Darling } \\
{[23]}\end{array}$ & $\begin{array}{c}\text { This work } \\
\mathrm{Eq}(16)\end{array}$ & $\begin{array}{c}\text { Estimated } \\
\text { Eq (21) }\end{array}$ \\
\hline 0 & 0 & 0 & 0 & 0 \\
50 & 0.0444 & & 0.0440 & 0.0438 \\
100 & 0.0895 & 0.063 & 0.0891 & 0.0892 \\
200 & 0.1822 & 0.140 & 0.1822 & 0.1828 \\
300 & 0.2782 & 0.23 & 0.2786 & 0.2795 \\
400 & 0.3774 & 0.32 & 0.3780 & 0.3791 \\
500 & 0.4798 & 0.43 & 0.4804 & 0.4807 \\
\hline
\end{tabular}

\section{Summary and Conclusions}

In this paper, we have described in some detail our realization of the Merritt-Saunders technique for the measurement of linear thermal expansion over the temperature range $-27^{\circ} \mathrm{C}$ to $550^{\circ} \mathrm{C}$. We report measurements, using this method, made on platinum and two platinum-rhodium alloys. We believe that the equation fitted to the experimental data of each sample accurately represents its linear thermal expansion to within $1 \mathrm{ppm}$ of sample length. Our data (some 86 points for three samples) show scatter from the fitting equations that is (with one exception) not larger than $2 \mathrm{ppm}$.

We have expended considerable effort to fit our data carefully and to record clearly the fitting parameters in order that the reader who may wish to utilize our results will be better able to judge their applicability. We have taken care to clearly define our terminology after noting that the clarity of thermal expansion nomenclature in the literature is not always adequate for the user's needs.

Where possible, we have compared our results with those of other experimenters. We have made these comparisons in terms of the linear thermal expansion, $\epsilon\left(t, t_{\mathrm{ref}}\right)$, even in those instances in which the authors have given an analytical representation of the experimental data in terms of the coefficient of linear thermal expansion, $\alpha\left(t, t_{\text {ref }}\right)$, (e.g. Holborn and Day [26] for $100 \% \mathrm{Pt}$ ). We chose to do so because we find this form of comparison to be the most useful for out needs and anticipate that it will be the information most sought by the reader. With the exception of the data of Barter and Darling [23] for the $(80 \mathrm{wt} \% \mathrm{Pt}+20 \mathrm{wt} \% \mathrm{Rh})$ alloy, we find agreement with other results within $\pm 20 \mathrm{ppm}$ throughout the temperature range of our experiments.

Finally, we have shown a close correspondence between the measured linear thermal expansion of two Pt-Rh alloys and values estimated by adopting a linear approximation using pure $\mathrm{Pt}$ and pure $\mathrm{Rh}$ thermal expansion data.

We are greatly indebted to L. A. Guildner for the design of the thermal expansion apparatus described herein and for his supervision of the experimental measurements. 


\section{Journal of Research of the National Bureau of Standards}

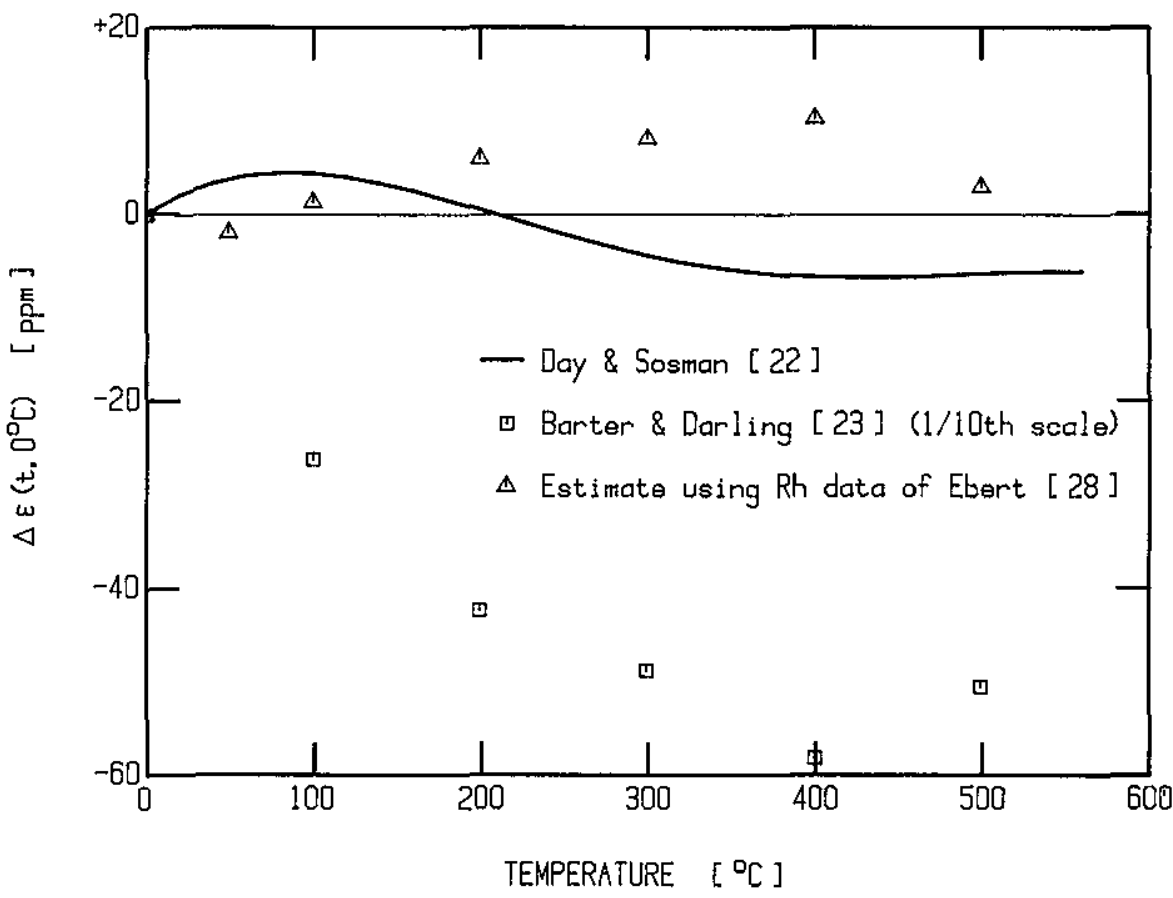

Figure 10-The differences between various published representations for the linear thermal expansion of $(80 \mathrm{wt} \% \mathrm{Pt}+20$ wt\% $\mathrm{Rh}$ ) and that obtained in this research.

\section{References}

[1] Clothier, W. K., A calculable standard of capacitance, Metrologia 1 36-55 (1965).

[2] Driscoll, R. L., Measurement of a current with a Pellattype electrodynamometer, J. Res. NBS 60 287-296 (1958).

[3] Bell, G. A., and J. B. Patterson, Density standards-the density and thermal dilatation of water, Precision Measurement and Fundamental Constants II, Taylor, B. N., and W. D. Phillips, eds, NBS (U.S.) Spec. Pub. 617 445447 (1984).

[4] Touloukian, Y. S.; R. K. Kirby, R. E. Taylor, and P. D. Desai, Thermal Expansion, Metallic Elements and Alloys, vol 12 in Thermophysical Properties of Matter, Touloukian, Y. S., and Ho, C. Y., eds, Plenum Press, New York, 1975.

[5] MacDonald R. A., and W. M. MacDonald, Thermodynamic properties of fcc metals at high temperatures, Phys. Rev. B 24 1715-1724 (1981).

[6] Collins J. G., and G. K. White, Thermal expansion of solids, Ch IX in Progress in Low Temperature Physics, vol IV, 1964, North-Holland Pub. Co., Amsterdam, pp. 450-479.

[7] Yates, B., Thermal Expansion, Plenum Press, New York, 1972, $121 \mathrm{pp}$.

[8] Waterhouse, N., and B. Yates, The interferometric measurement of the thermal expansion of silver and palladium at low temperatures, Cryogenics 8 267-271 (1968).

[9] Andres, K., The measurement of thermal expansion of metals at low temperatures, Cryogenics 2 93-97 (1961).

[10] Shapiro, J. M.; D. R. Taylor, and G. M. Graham, A sensitive dilatometer for use at low temperatures, Can. J. Phys. 42 835-847 (1964).

[11] Batchelder, D. N., and R. O. Simmons, X-ray lattice constants of crystals by a rotating-camera method: $\mathrm{Al}, \mathrm{Ar}$, $\mathrm{Au}, \mathrm{CaF}_{2}, \mathrm{Cu}, \mathrm{Ge}, \mathrm{Ne}, \mathrm{Si}, \mathrm{J}$. Appl. Phys. 36 2864-2868 (1965).

[12] White, G. K., Measurement of thermal expansion at low temperatures, Cryogenics 1 151-158 (1961).
[13] Carr, R. H., and C. A. Swenson, Application of a variable transformer to the study of low temperature thermal expansion, Cryogenics 4 76-82 (1964).

[14] Commercially available products are identified herein only for the sake of accurate description. No implication is intended that these items are superior to others of the same type, or that the NBS endorses the use of these products.

[15] Candler, C., Modern Interferometers, Hilger \& Watts, Ltd., 1951, Ch IV.

[16] Merritt, G. E., Application of the interferometer to measurements of the thermal dilatation of ceramic materials, Scientific Papers of the Bureau of Standards 19 No. 485 (1924).

[17] Saunders, J. B., An apparatus for photographing interference phenomena, NBS Research Paper RP1668, J. Res. NBS 35 157-186 (1945).

[18] The International Practical Temperature Scale of 1968; amended Edition of 1975, Metrologia 12 7-17 (1976).

[19] Cutkosky, R. D., An a-c resistance thermometer bridge, J. Res. NBS 74c 15-18 (1970).

[20] Kaufmán, V. Wavelengths, energy levels, and pressure shifts in mercury 198, J. Opt. Soc. Am. 52 866-870 (1962).

[21] See, for example, American Inst. of Physics Handbook, 3rd Ed., Gram, D. E., ed, McGraw-Hill Book Co., New York, 1972, Ch 6.

[22] Mandel, J., The Statistical Analysis of Experimental Data, Wiley \& Sons, New York (1964) Ch 8.

[23] Barter, B., and A. S. Darling, Thermal expansion of rhodium-platinum alloys, Platinum Metals Rev. 4 138-140 (1960).

[24] Hahn, T. A., and R. K. Kirby, Thermal expansion of platinum from 293 to $1900 \mathrm{~K}$, in Thermal Expansion--1971, Grahm, M. G., and H. E. Hagy, eds; Amer. Inst. of Phys. Conf. Proc. \#3, Wolfe, H. C., Series ed, Amer. Inst. ofPhys., New York, 1972, pp. 87-95. 


\section{Journal of Research of the National Bureau of Standards}

[25] MacDonald, R. A., The thermal expansion coefficient of fcc metals, in Thermal Expansion 8, the Proceedings of the 8th International Thermal Expansion Symposium, Gaithersburg, Maryland, 1981, Plenum Press, New York, 1984, pp. 11-19.

[26] Holborn, L., and A. L. Day, On the expansion of certain metals at high temperatures, Amer. J. Sci., 4th Series 11 374-390 (1901).

[27] Day, A. L., and R. B. Sosman, The nitrogen thermometer from zinc to palladium, Amer. J. Sci., 4th Series 29 93161 (1910).

[28] Ebert H., Bestimmung der Wärmeausdehnung von einigen aluminium- und magnesium-legierungen, sowie vom rhodium, Phys. Zeit. 39 6-9 (1938). 